\title{
PINTURAS, ESCULTURAS Y OTROS OBJETOS EN EL INVENTARIO DE BIENES REALIZADO A LA MUERTE DE DOÑA CARLOTA JOAQUINA DE BORBÓN*
}

\author{
Clara Moura Soares ${ }^{1}$ \\ Universidade de Lisboa
}

\begin{abstract}
En este artículo se presenta y analiza el inventario de bienes de la reina Carlota Joaquina realizado en 1835, pasados cinco años de su fallecimiento, en particular todo lo relativo a la colección de pintura, además de otras obras de arte y objetos notables. A partir de algunos documentos inéditos y de la reinterpretación de otros ya publicados, se añaden nuevos datos al conocimiento de la herencia de la soberana portuguesa, hija y heredera de Carlos IV de España, lo cual permitirá establecer las oportunas correspondencias tanto con piezas que habían pertenecido a las colecciones de su padre como con otras que, tras su muerte, fueron a parar a colecciones públicas y privadas.
\end{abstract}

Palabras clave: Carlota Joaquina; colección de pintura; inventario de bienes; herencia; subasta; Portugal.

\section{PAINTINGS, SCULPTURES AND OTHER OBJECTS IN THE INVENTORY OF GOODS CARRIED OUT BY DEATH OF D. CARLOTA JOAQUINA OF BOURBON}

The aim of this article is to present and analyse the contents of the inventory of goods carried out in 1835, five years after the death of queen Carlota Joaquina, in particular the collection of paintings, but also other pieces of art and notable objects. Through some unpublished documentation and the reinterpretation of other known papers, new data were discovered about the inheritance of the Portuguese sovereign, daughter and heiress of Carlos IV of Spain. This allowed for tracing pieces that belonged to her father's collection, and also the ones that were added to public and private collections after her death.

Key words: Carlota Joaquina; painting collection; inventory of goods; inheritance; auction; Portugal.

Cómo citar este artículo / Citation: Soares, Clara Moura (2020): "Pinturas, esculturas y otros objetos en el inventario de bienes realizado a la muerte de doña Carlota Joaquina de Borbón”. En: Archivo Español de Arte, vol. 93, núm. 369, Madrid, pp. 1-20. https://doi.org/10.3989/aearte.2020.01.

\section{Una heredera de Carlos IV de España}

Carlota Joaquina de Borbón (1775-1830), reina consorte del Reino Unido de Portugal, Brasil y Algarbes tras su matrimonio con el infante don Juan - futuro Juan VI de Portugal (17671826) - , era la primogénita del monarca español Carlos IV (1748-1819) y de su esposa María Luisa de Parma (1751-1819). La infanta nació en el Palacio Real de Aranjuez y permaneció en España hasta los 10 años, cuando se trasladó a Portugal para formalizar su matrimonio con don Juan. De esos primeros años nos han llegado retratos suyos de algunos artistas de prestigio, como

\footnotetext{
* Este trabajo completa lo publicado por esta misma autora en portugués, Soares, 2017. Traducción: J. León Acosta.
}

1 claramourasoares@letras.ulisboa.pt / ORCID iD: http://orcid.org/0000-0002-4130-2158. 
Anton Raphael Mengs (c. 1775) y Mariano Salvador Maella (1785), a los que se fueron uniendo a lo largo de su vida otros pintados por Domingos António de Sequeira, Jean-Baptiste Debret, Nicolas-Antoine Taunay, Manuel Dias de Oliveira, Giuseppe Trono, João Baptista Ribeiro o Luis de la Cruz [fig. 1].

Carlota Joaquina llegó a Portugal muy joven, tanto que necesitó un permiso especial del Papa, no solo porque todavía le faltaban más de dos años para poder contraer matrimonio, sino también debido a los lazos familiares que le unían al infante don Juan ${ }^{2}$ [fig. 2]. A pesar de su corta edad, sus conocimientos eran notables, como dan fe los exámenes literarios a que fue sometida antes de encaminarse a la corte portuguesa ${ }^{3}$.

Sobre los talentos artísticos de la infanta española, el pintor portugués Cyrillo Volkmar Machado (1748-1823) declaraba que "Es bien sabido de todos el talento poco común que tiene la Reina, la Señora Doña Carlota Joaquina, para las ciencias y las bellas artes. Con pocas lecciones ha hecho grandes progresos en el dibujo y la pintura al óleo y al pastel. Y, si no ha creado muchas obras de esta naturaleza, ha sido porque empleaba el tiempo aún mejor en la excelente educación que supo dar a sus Augustas Hijas, que también aprendieron a dibujar"4.

Sabemos que era de su autoría el cuadro Figura popular (1795), actualmente en el Palacio Nacional de Ajuda, en Lisboa ${ }^{5}$, además de Mujer española con montera y San Francisco, los cuales han desaparecido ${ }^{6}$.

Del padre había heredado el gusto por el arte y el coleccionismo, y en primer lugar la pintura, una faceta del soberano español que las investigaciones llevadas a cabo en los últimos años han ido sacando a la luz ${ }^{7}$. Sobre la constitución de la pinacoteca de Carlota Joaquina se sabe muy poco, a no ser el papel determinante desempeñado en algunas mediaciones y adquisiciones por destacados diplomáticos portugueses, como Rodrigo de Sousa Coutinho (1 er $^{\text {er }}$ conde de Linhares), António de Araújo e Azevedo (conde da Barca) o el embajador portugués en Viena, Lourenço de Lima - este último, al parecer, fue decisivo en la adquisición de la colección del príncipe de Ligne (Países Bajos) entre 1794 y 1798, rica en obras flamencas ${ }^{8}$-, y la circunstancia de haber heredado algunas obras pertenecientes a la apreciable colección de su padre.

Cuando Carlos IV muere el 19 de enero de 1819 en Nápoles, pocos días después del fallecimiento de su esposa, la colección de pintura del exmonarca - exilado en Italia como resultado de las invasiones francesas - sobrepasaba las mil quinientas obras, todo ello fruto de un "afán coleccionista casi obsesivo", como señala Carmen García-Frías 9 . Entre esas obras se contaban originales y copias, obras antiguas y modernas de escuelas y artistas italianos, flamencos, alemanes, holandeses, españoles y franceses ${ }^{10}$. Los diversos inventarios realizados nos permiten conocer con detalle dicha colección, tanto sobre las obras reunidas en España - en la Casita del Príncipe, de El Escorial, y en el Real Sitio de Aranjuez ${ }^{11}$ - como sobre las adquiridas durante el exilio italiano, que adornaron los palacios de Barberini, Sant'Alessio y Albano ${ }^{12}$.

En su correspondencia diplomática, que aquí damos a conocer, Camilo Luiz Rossi, cónsul de Portugal en Roma, irá poniendo a las autoridades portuguesas al tanto de los acontecimientos, al tiempo que dejaba constancia de las dificultades que iba encontrando, en las fechas inmediatamente posteriores a la muerte de Carlos IV, para conocer los términos de sus disposiciones tes-

\footnotetext{
2 "Carta do Marquês de Louriçal para D. Diogo de Noronha", 3 de julio de 1784. Arquivo Nacional da Torre do Tombo (ANTT), en Lisboa, Ministério dos Negócios Estrangeiros (MNE), Caja 634.

3 Gazeta de Lisboa, n. ${ }^{\circ}$ 40, 4-X-1785, pp. 3-4.

4 Machado, 1823: 38-39. Traducido del texto original portugués.

5 Doña Carlota Joaquina, Figura popular, 1795. Palácio Nacional da Ajuda (PNA), Inv. 2930.

${ }^{6}$ Probablemente desaparecieron durante el incendio que se desató en el PNA en 1974. Carvalho, 1982: 24.

7 Hermoso Cuesta, 2005; 2010. Sancho, 2008. Jordán de Urríes, 2009. García-Frías, 2011.

8 Blanco, 1938: 147-151.

9 García-Frías, 2011: 211.

10 García-Frías, 2011: 211-261. Urriagli Serrano, 2012: 137-572.

11 Urriagli Serrano, 2012.

12 Villa-Urrutia, 1919. Hermoso Cuesta, 2010: 200.
} 


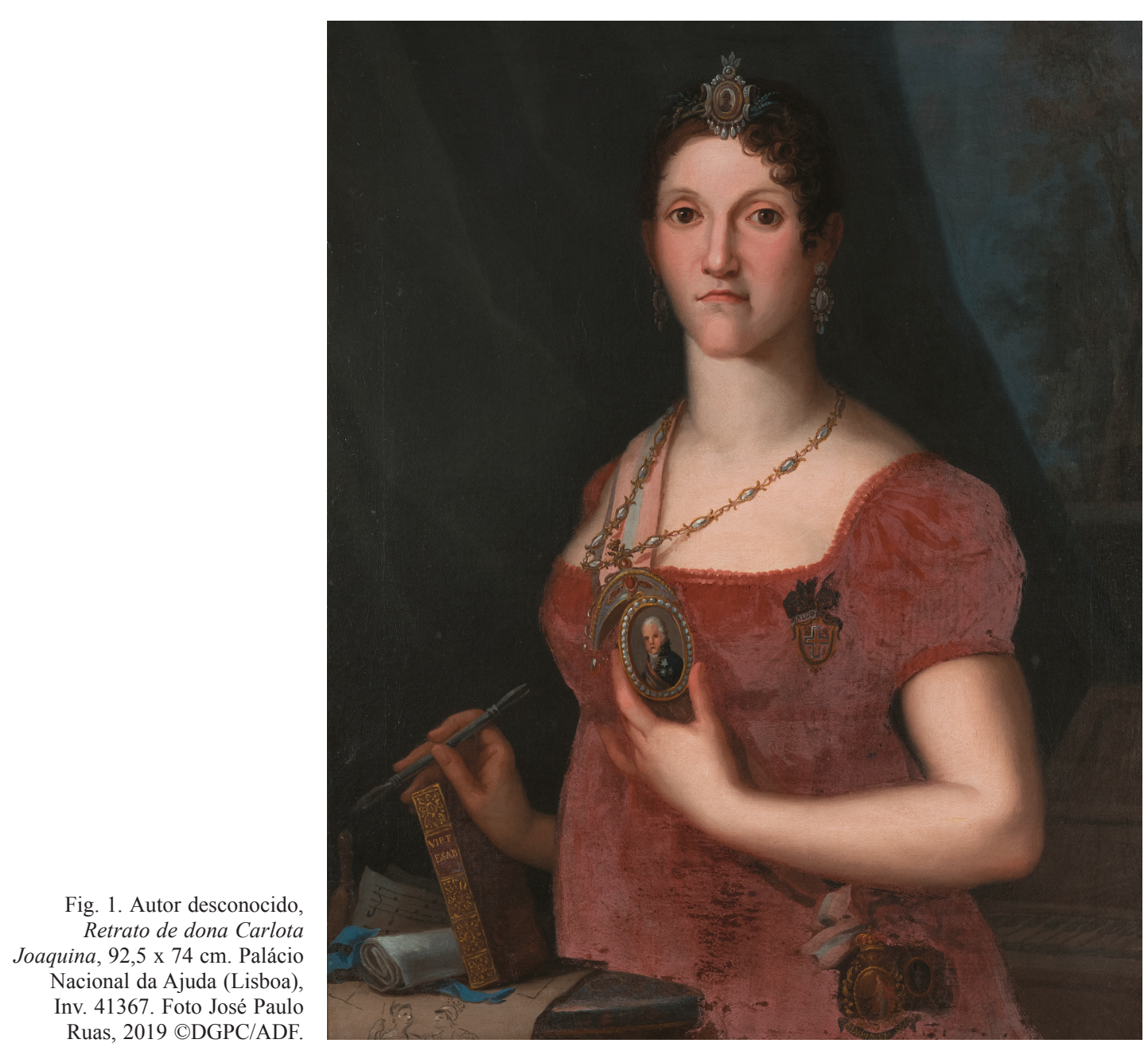

tamentarias ${ }^{13}$. Tras sopesar la posibilidad de que Carlos IV no hubiera llegado a concluir la escritura de su testamento por haber sido mantenida en secreto, su mayordomo, el marqués de San Martín, informó al cónsul portugués que el exmonarca español había requerido la presencia de un notario en su lecho de muerte para pedirle que dejase constancia de su intención de anular el testamento que había hecho años atrás, en el cual recompensaba generosamente al 'Príncipe de la Paz', Manuel de Godoy. Añade el diplomático que la intención del monarca no habría sido redactar un nuevo testamento formal, sino dejar por escrito algunas disposiciones nuevas. Entre estas destacan la que instituye a Fernando VII como su heredero universal y la que establece que "las joyas particulares del Rey y de S.M. la Reina Doña María Luisa (que son de grandísima consideración) [serán] repartidas entre sus Augustos Hijos e Hijas, y que dejaba al Rey Fernando VII el cuidado de su partición"14. En cuanto a "su rica Colección de Cuadros" y tantos otros bienes y rentas que poseía, no existe ninguna mención particular, como advierte Camilo de Rossi ${ }^{15}$.

13 "Carta do Cônsul de Portugal em Roma”, 11 de marzo de 1819. ANTT, MNE, caja 316.

14 "Carta do Cônsul de Portugal em Roma", 30 de enero de 1819. ANTT, MNE, caja 316. Traducción del texto original portugués.

15 "Carta do Cônsul de Portugal em Roma”, 11 de marzo de 1819. ANTT, MNE, caja 316. Traducción del texto original portugués. 


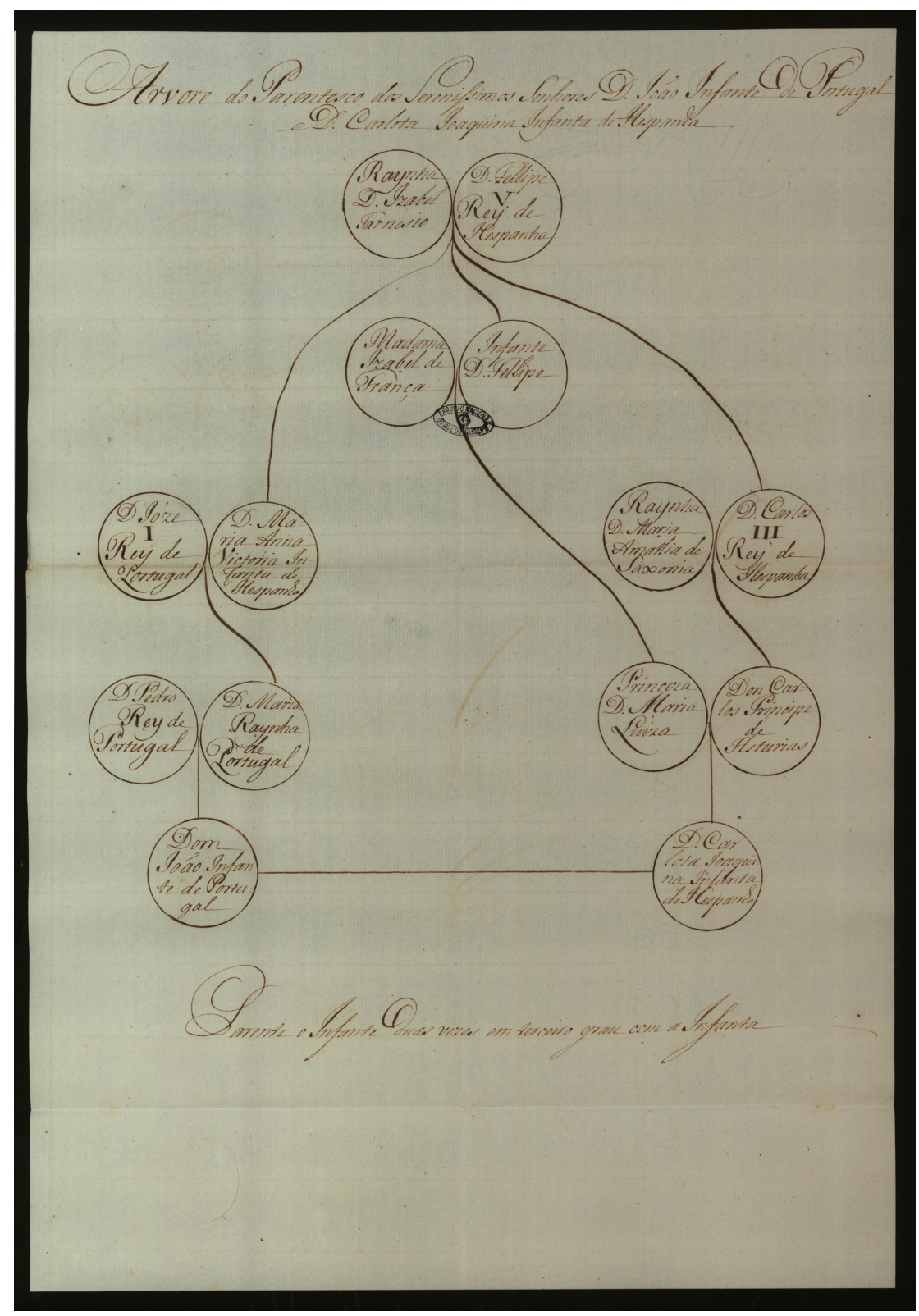

Fig. 2. Árbol del parentesco de los

Serenísimos Señores Don Juan, Infante de Portugal, y Doña Carlota Joaquina, Infanta de España.

Correspondencia de la

legacía portuguesa en

Madrid. ANTT (Lisboa),

MNE, caja 634. CANTT

Hoy se sabe que, de la magnífica colección de pintura de Carlos IV, cuyo reparto se inicia solo a partir del 1 de abril de $1826^{16}$, a Carlota Joaquina le correspondió en herencia un lote que finalmente se destinaría a ornamentar las salas del Palacio de Ramalhão, propiedad particular que la reina poseía en Sintra. Dichas obras, registradas en el tercer lote del lega$\mathrm{do}^{17}$ —el cual acabaría por ser atribuido a la soberana portuguesa, una vez que Fernando VII, el único heredero que podía elegir su parte, expresó su preferencia por los muebles, relojes y otros objetos ${ }^{18}$-, tardarían en llegar a Portugal debido a los retrasos en la ejecución de la

\footnotetext{
16 García-Frías, 2011: 231, 234.

17 Se prevén nuevas publicaciones de Carmen García-Frías sobre este mismo tema. Bastos, 2014: 26-27, nota 1.

18 García-Frías, 2011: 212, 232.
} 
herencia. Dejando a un lado el Éxtasis de San Francisco de Luca Giordano ${ }^{19}$, las dos Marinas del paisajista francés Claude-Joseph Vernet ${ }^{20}$ y una copia del San Miguel de Guido Reni, pintada en Roma por Juan Antonio de Ribera ${ }^{21}$, poco más se sabe sobre cuáles de esas obras heredadas - y cuándo - acabaron por completar y engrandecer la ya significativa colección de 180 cuadros que Carlota Joaquina poseía en la 'Casa de la Pintura' del Palacio de Ramalhão, de acuerdo con un inventario realizado en 1807, cuando la Corte portuguesa se preparaba para el exilio en Brasil ${ }^{22}$. En la correspondencia diplomática no aparecen referencias sobre el asunto y el análisis de los inventarios de Carlos IV aún no nos ha permitido obtener resultados concluyentes ${ }^{23}$. Se sabe, sin embargo, que no debió de ocurrir mucho antes de la muerte de la soberana, ya que el 12 de mayo de 1828 los cuadros aún permanecían en Madrid. José Presas y Marull, antiguo secretario de doña Carlota Joaquina, llega a plantear la posibilidad de que se vendieran, a fin de evitar su degradación o incluso su desaparición, como ya había ocurrido con "la mejor de ellas", según refiere, debido a las condiciones de almacenamiento y a la falta de vigilancia ${ }^{24}$.

\section{La muerte de Carlota Joaquina y la compleja administración de su herencia}

Carlota Joaquina falleció el 7 de enero de 1830 en el Palacio de Queluz a la edad de 54 años. Por voluntad testamentaria de la emperatriz-reina redactada ese mismo día, su hijo predilecto, don Miguel, sería nombrado albacea y legatario fundamental de su herencia, estándole reservados, entre otros bienes, todos los que pertenecían al Palacio de Ramalhão 25 .

Todavía no se habían iniciado los inventarios de bienes cuando el 26 de mayo de 1834 se firma la Convención de Évora Monte, cuyas consecuencias inmediatas fueron poner punto final a la guerra civil portuguesa entre liberales - liderados por don Pedro, duque de Braganza- y absolutistas - capitaneados por don Miguel-, otorgar a don Pedro el estatuto de heredero legítimo de la corona y formalizar los términos de la rendición de don Miguel: pérdida de su estatuto real, condena al exilio e interdicción de regresar a Portugal ${ }^{26}$.

La muerte del duque de Braganza el 24 de septiembre de ese mismo año acabaría por determinar que fuera su mujer y testamentaria, doña Amelia de Leuchtenberg, quien tratase del reparto de los bienes de doña Carlota Joaquina entre los legítimos herederos. En Consejo de Familia se propuso conceder "permiso para vender la quinta de Ramalhão [...] con todos sus bienes anexos, muebles y semovientes, como se halla descrito en el Inventario" ${ }^{27}$. De las respectivas

\footnotetext{
19 Esta obra en particular tuvo que ser reclamada por doña Carlota Joaquina en enero de 1827, ya que, a pesar de estar registrada como parte de su herencia, había sido depositada en el Museo del Prado. Hermoso Cuesta, 2010: 198199, 203-207.

${ }^{20}$ García-Frías, 2011: 227-228 y 245. Las tres obras mencionadas forman parte de la colección del Museo Nacional de Arte Antigua (MNAA), Inv. 179 Pint., 467 Pint. y 468 Pint.

21 ANTT, Tribunal Judicial da Comarca de Lisboa, 6. ${ }^{a}$ Vara, 2. ${ }^{a}$ Sección, mazo 8, caja 21, sala 1, cuerpo 56, apéndices 64 y 71. Podría tratarse del cuadro n. ${ }^{\circ} 119$ del inventario de pintura de Carlos IV referido por García-Frías, 2011: 228, nota 122. Cf. Bastos, 2014: 30, nota 42.

22 Inventário de toda a mobilia que Existe no Real Paço do Ramalhão da Princeza N. Snr ${ }^{a}$ feito em Julho de $=1807=$. ANTT, Casa das Rainhas, Libro 234 .

${ }_{23}$ Nos referimos a los inventarios publicados por Diana Urriagli Serrano. No obstante, sería de gran utilidad confrontar los inventarios de las disposiciones testamentarias de Carlos IV en Roma, cuyas copias se encuentran en los archivos de Madrid, ya que una parte de los cuadros de esa "colección romana" fueron heredados por la reina consorte de Portugal.

24 Presas, 1830: 277.

25 “Testamento de D. Carlota Joaquina de Bourbon, Imperatriz do Brasil e Rainha de Portugal”, 7 de enero de 1830. ANTT, Gavetas, Gaveta 16, mazo 3, n. ${ }^{\circ} 18$.

${ }^{26}$ Soares, 2014b: 381-398.

27 "Documentos de Despesa da Casa Real e Outros, Auto do Conselho de Família", 12 de mayo de 1835. ANTT, Casa Real (CR), caja 4663.
} 
particiones, según lo establecido en las disposiciones del testamento, cabría la mitad a la emperatriz Amelia, además de un tercio de la otra mitad, siendo los restantes dos tercios divididos en partes iguales entre los cinco hijos del fallecido duque de Braganza.

La ejecución de la herencia se arrastraría en el tiempo debido a las dificultades que fueron surgiendo. Una vez que se produce la renuncia de la viuda del monarca portugués en enero de 1838, fue designada como albacea sucesiva María II, hija primogénita de don Pedro IV - I de Brasil - y nieta de Carlota Joaquina. Tras la muerte de María II el 15 de noviembre de 1853, pasaría a desempeñar sus funciones el rey consorte, Fernando II de Sajonia-Coburgo-Gotha ${ }^{28}$, ya que las subastas se habían prolongado más allá de esa fecha.

La elaboración de los inventarios de la herencia, iniciados el 23 de febrero de 1835 y concluidos en menos de un mes, el 10 de marzo, parece no haber sido tarea fácil, atendiendo a la cantidad y diversidad de objetos comprendidos. Su finalización, con las respectivas tasaciones de los lotes, acabaría por crear las condiciones para acordar la venta pública de todos los bienes, lo que llevó a su traslado al palacio de Bemposta, en Lisboa, que había sido la residencia oficial de Juan VI, y donde serían finalmente expuestos y subastados. En cuanto al Palacio de Ramalhão, se dispuso su arrendamiento en subasta pública, con la justificación de que su mantenimiento resultaba muy oneroso ${ }^{29}$.

\section{El inventario de los bienes (1835)}

La muerte de don Pedro desencadenaría, finalmente, el proceso de inventariado de los bienes de Carlota Joaquina, motivo que no ha sido apuntado por los especialistas para justificar que solo en 1835 tuviera lugar su inicio ${ }^{30}$. Se comenzó por los cuadros dispuestos en la 'segunda sala' del Palacio de Ramalhão, en la planta noble, donde también se hallaban las mejores piezas de escultura. Más de treinta salas de esa misma planta estaban también repletas de mobiliario y otras piezas decorativas (relojes, joyeros, piezas de marfil), así como en la ermita, donde estaban dispuestas varias cruces, paramentos, candelabros, un sagrario y una maquinilla. En el piso inferior, en las denominadas "Casas de Abajo Interiores", se hallaba un conjunto de más de trescientas piezas de uso cotidiano, del que formaban parte muebles, "loza inglesa", piezas de cobre, ropa, vidrios y cristales. De entre ese total de 765 lotes inventariados, habría que destacar también algunas propiedades inmuebles, como el propio Palacio de Ramalhão.

La colección de pintura constituía, sin duda alguna, el núcleo principal del acervo artístico acumulado por la soberana, del que también formaba parte un número muy considerable de estampas, algunas esculturas, piezas de marfil, porcelanas y relojes.

En 1836, António Manuel da Fonseca ${ }^{31}$ — Profesor de Pintura de Historia de la Real Academia de Bellas Artes- y Luis Tirinnanzi ${ }^{32}$ - pintor-restaurador italiano, bastante conocido en España a partir de 1850 como anticuario y "profundo conocedor y evaluador de cuadros antiguos" 33 - fueron los expertos aprobados por el Consejo de Familia para proceder al inventario y tasación de la pinacoteca de doña Carlota Joaquina ${ }^{34}$. Los maestros José María Benavides y Bartholomeu Dejeant se encargarían de evaluar las piezas de ebanistería; Francisco de Paula Hertz, de la ropa y los tejidos; João José de Sousa Baptista, de las vajillas y los cristales; el

28 Bastos, 2014: 4.

29 Soares, 2017.

${ }^{30}$ Los inventarios, o sus copias, se encuentran en el ANTT, CR, cajas 4663 y 7311, además de en ANTT, Tribunal

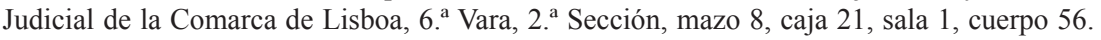

31 Alves, 2015: 97-105.

32 Pintor-restaurador florentino establecido en Lisboa desde 1815 bajo la protección del 1 . $^{\text {er }}$ conde de Farrobo. Araújo, 2009: 33-38.

33 Reyero, 2014: 161.

34 Fonseca fue uno de los pintores incumbidos de inventariar las obras pictóricas, procedentes de los conventos extinguidos. Soares, 2014a: 200-201. 
contraste Luís Pedro Lourenço, de la plata, el oro y las joyas; y el maestro Miguel Vielle, de los relojes ${ }^{35}$.

Los peritos elegidos se comprometían "en buena conciencia, sin dolo, malicia, soborno u otro motivo" a "tasar los bienes conforme a su calidad, estado y uso" 36 .

En cuanto a la pintura, y gracias al informe elaborado, se consigue determinar la naturaleza de la colección y de las obras que la integraban ${ }^{37}$. En dicho documento se identifican temas, materiales y medidas (en palmos ${ }^{38}$ ) y se hacen numerosas atribuciones a diferentes autores, acompañadas además por algunas apreciaciones estéticas, así como por indicaciones sobre el estado de conservación de parte de ellas ${ }^{39}$.

El conjunto está compuesto por cerca de 190 pinturas y casi centenar y medio de estampas, estas últimas predominantemente de temática profana (retratos, paisajes, batallas, de género), estando algunas de ellas 'iluminadas'. Del conjunto formaban parte varias estampas en que aparecían representados miembros de la familia real española (Fernando VII, Isabel Francisca, Carlos María), aunque también las hay de don Pedro de Braganza, Leopoldina o el duque de Wellington, así como de obras de diversos artistas de renombre, entre las que cabe destacar una Cena del Señor, de Leonardo da Vinci, el Avaro, de Rembrandt, o varios paisajes de Claude Lorrain.

Aunque la mayoría de los cuadros están pintados sobre lienzo, también hay incluidas veinte tablas, dos de ellas identificadas como de "figura gothica" 40 , además de algunas sobre otros soportes, como cobre, cartón, pergamino o mosaico. Este último corresponde a un retrato del pontífice Pío VI, de "forma ovalada con 4 medallas redondas pequeñas en los ángulos, vistas de Roma con sus marcos de bronce dorados" 41 .

En cuanto a los temas representados, identificamos un predominio de la pintura religiosa, hecho al que no habría sido indiferente el fervor católico de la soberana. La pintura paisajística - con escenarios bucólicos y marítimos-, de género y el retrato completan el repertorio, siendo escasos los temas mitológicos y alegóricos ${ }^{42}$.

La pinacoteca, extremadamente ecléctica, reunía originales y copias - algunas de ellas consideradas por los peritos que las evaluaron como de mala o muy mala calidad - y obras antiguas y contemporáneas en las que se observa un evidente predominio de la pintura italiana de los siglos XVI y XVII [figs. 3 y 4]. Dentro de esta surgen obras que se consideran originales "de la sublime y primera manera de Rafael", de la escuela de Leonardo da Vinci y de otros pintores del siglo XVI — como Tiziano, Ugo da Carpi, Bronzino, Veronés, Perino del Vaga o Parmigianino-, así como de pintores del siglo XVII como Caravaggio, Carracci, Domenichino, Guido Reni, Pietro da Cortona, Sassoferrato o Salvator Rosa. Le siguen los artistas españoles del siglo XVII: un Retrato de un Juez ${ }^{43}$, atribuido a Velázquez [fig. 5]; Jesucristo en brazos del Padre Eterno, de Ribera; un bosquejo de Murillo de la Presentación en el Templo; y dos naturalezas muertas de Antonio Pereda, tituladas Fruteros con diversos utensilios ${ }^{44}$ [fig. 6].

A este núcleo le siguen los pintores franceses (Nicolas Poussin, Claude Lorrain, Vernet, Pillement), holandeses (Lucas van Leyden, Rembrandt) y los maestros flamencos del siglo XVII

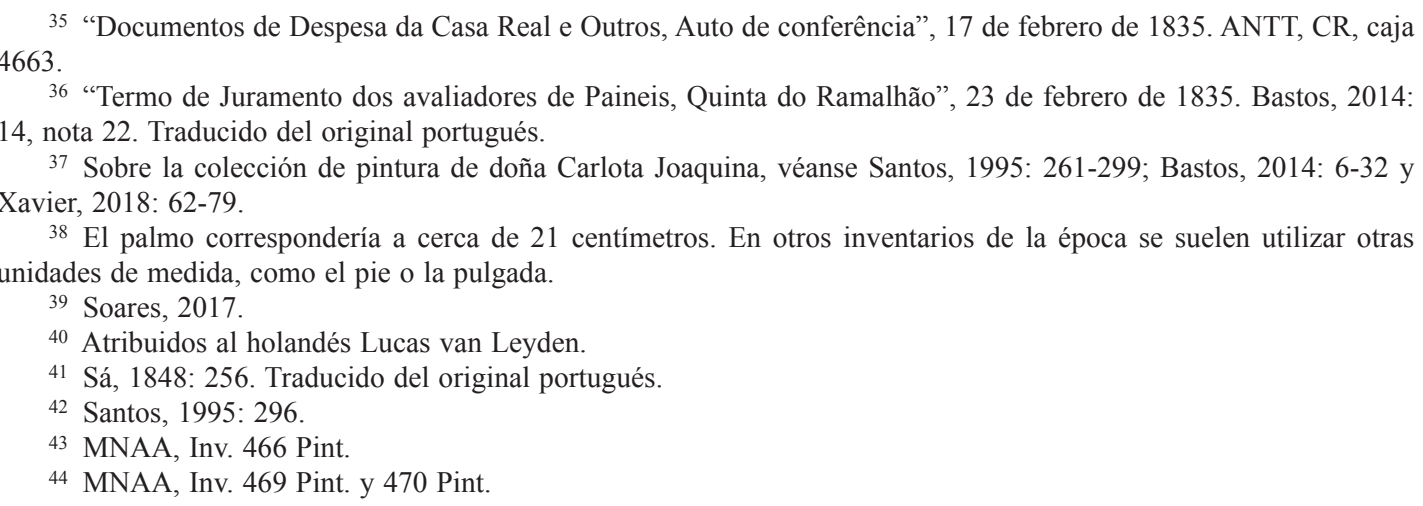



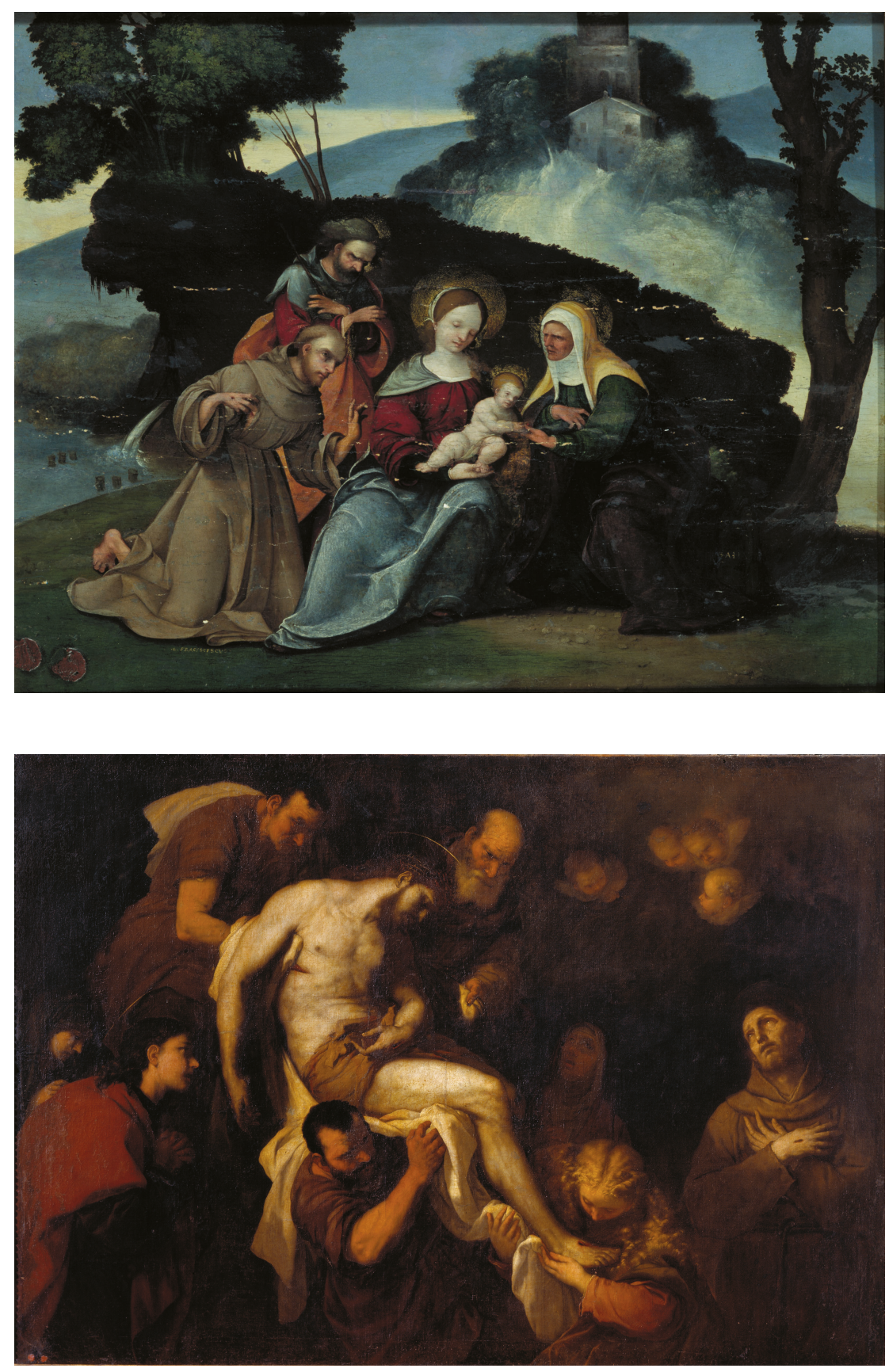

Fig. 3. Ludovico Mazzolino (at.), Sagrada Familia, Santa Ana y San Francisco, s. XVI, 36 x $44,5 \mathrm{~cm}$. MNAA (Lisboa), Inv. 460 Pint. Foto José Pessoa, 1994 CDGPC/ADF.
Fig. 4. Luca Giordano, Éxtasis de San

Francisco, c. 1660-1690, $182 \times 257 \mathrm{~cm}$. MNAA Inv. 719 Pint. Foto José Pessoa, 2003 CDGPC/ ADF.

(Rubens, Jan Brueghel, David Teniers). La casi nula presencia portuguesa se compensa con un San Francisco en éxtasis y ángeles, de Domingos António de Sequeira, y dos estampas de Vieira Portuense, Juramento de Viriato y La Sagrada Familia. Llama la atención la aparente ausencia de obras de artistas brasileños, que podrían eventualmente haber sido traídas en 1821 desde Río de Janeiro, cuando la corte regresa a Portugal tras los catorce años de exilio provocado por las invasiones francesas.

La inclusión de pintores del siglo XVIII - como los italianos Placido Costanzi y Giuseppe Cades, de los paisajistas franceses Claude-Joseph Vernet y Jean-Baptiste Pillement o del neoclá- 


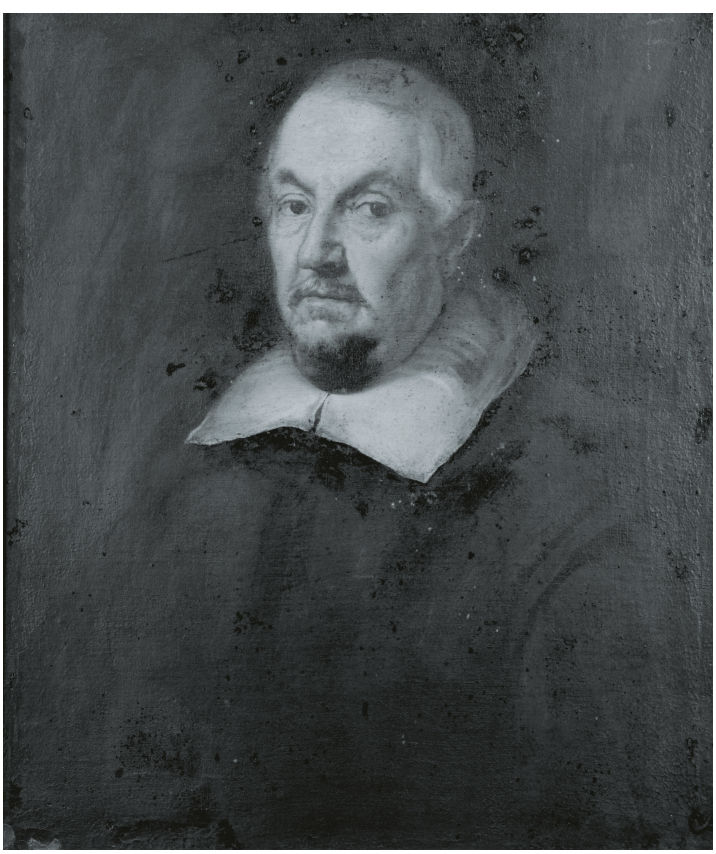

Fig. 5. Autor desconocido, Retrato de un personaje del siglo XVII, 74 x $62 \mathrm{~cm}$. MNAA, Inv. 466 Pint. Foto José Pessoa, 1995 CDGPC/ADF. sico Raphael Mengs - deja entrever cierto interés por obras de artistas 'modernos'.

En conjunto, los 'cuadros de autor' representan un núcleo particularmente relevante. El esfuerzo evidente por asociar una parte significativa de las obras del legado a grandes nombres de la pintura europea desde el siglo XV hasta inicios del XIX, en un momento en que se empezaban a dar los primeros pasos en la elaboración de historias de la pintura, repercutieron directamente en las evaluaciones y tasaciones presentadas.

Para tener una idea del conjunto, en la tabla siguiente sistematizamos las obras pertenecientes a la colección de pintura de Carlota Joaquina, seleccionadas a partir del inventario de 1835. Aparecen identificadas con el número de su ordenación y acompañadas de los temas y las autorías o atribuciones con que fueron registradas en su momento, así como sus respectivas dimensiones $^{45}$ :

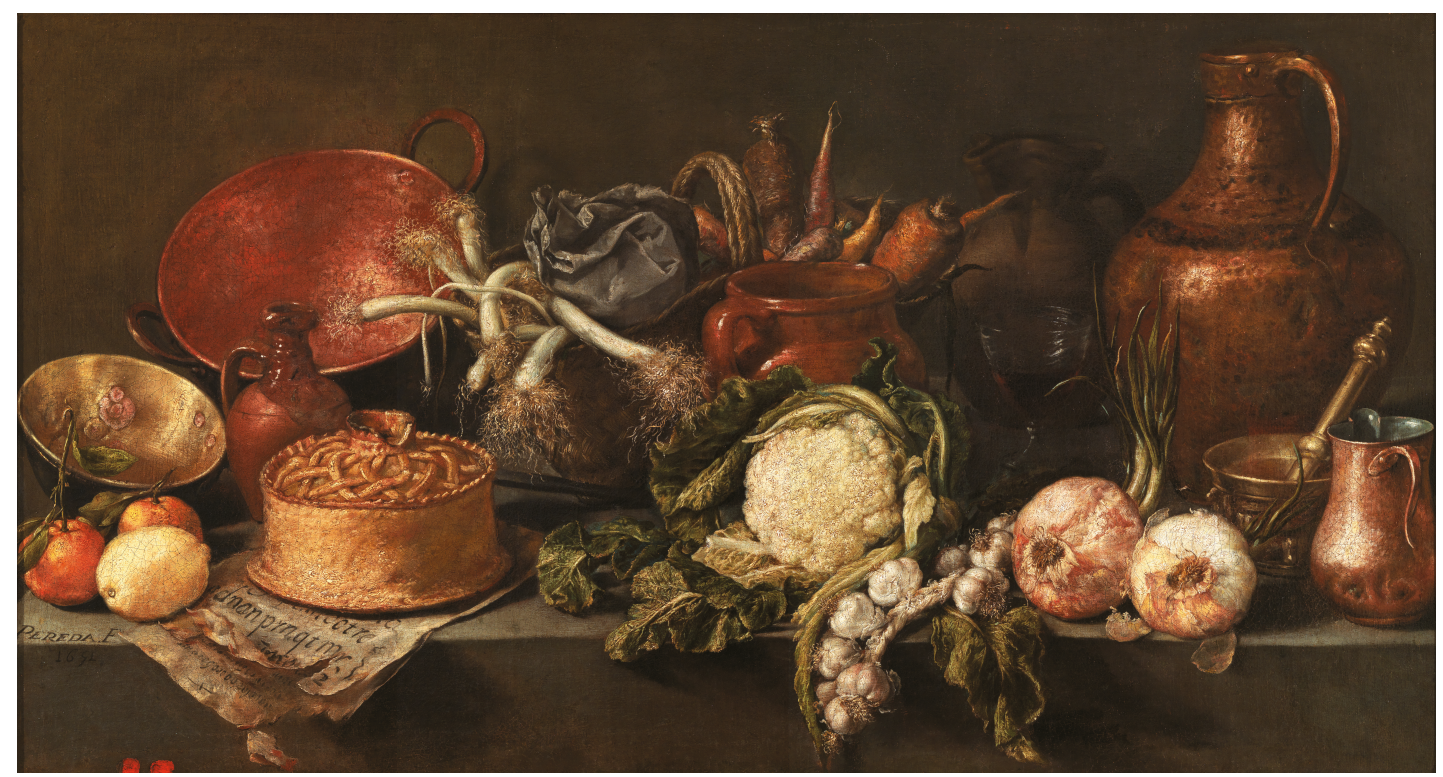

Fig. 6. Antonio Pereda y Salgado, Naturaleza muerta con empanada, verduras y utensilios de cocina, 1650, 75 x $143 \mathrm{~cm}$. MNAA, Inv. 470 Pint. Foto Luísa Oliveira, 2017 CDGPC/ADF.

${ }^{45}$ La relación de los cuadros del inventario fue publicada en el siglo XIX (Sá, 1848), elaborada a partir del rol más extenso, disponible en el ANTT, en los fondos documentales ya citados. El objetivo principal de ese inventario era impedir la dispersión de la colección, aunque no iba acompañado de ningún estudio crítico. En esta tabla hemos actualizado los nombres de los artistas para facilitar su identificación y se han suprimido las tasaciones, pues consideramos que no son relevantes para el presente estudio. 
Tabla I

\begin{tabular}{|c|c|c|c|}
\hline $\mathbf{N}^{\circ}$ & Cuadros / Temas representados & Autoría/Atribución & Dimensiones \\
\hline 1 & Viejo Pastor, medio cuerpo, lienzo & Pietro da Cortona & $\begin{array}{l}\text { ancho: } 2 \text { palmos y } 1 / 4 \\
\text { alto: } 2 \text { palmos y } 3 / 4\end{array}$ \\
\hline 2 & $\begin{array}{l}\text { Caballero a la antigua usanza, medio } \\
\text { cuerpo, lienzo }\end{array}$ & "Escuela Loilio" & $\begin{array}{l}\text { ancho: } 2 \text { palmos y } 3 / 4 \\
\text { alto: } 3 \text { palmos y } 1 / 4\end{array}$ \\
\hline 3 & $\begin{array}{l}\text { Retrato de un juez, medio cuerpo al natural, } \\
\text { lienzo }\end{array}$ & Caballero Velázquez & $\begin{array}{l}\text { ancho: } 2 \text { palmos y } 3 / 4 \\
\text { alto: } 3 \text { palmos e } 1 / 4\end{array}$ \\
\hline 4 & Baño de Diana, lienzo & Caballero de Arpino & $\begin{array}{l}\text { ancho: } 2 \text { palmos y } 1 / 4 \\
\text { alto: } 2 \text { palmos y } 3 / 4\end{array}$ \\
\hline 5 & $\begin{array}{l}2 \text { cuadros: Filósofo Esopo, pequeño cuadro, } \\
\text { tabla / Vulcano, pequeño cuadro, tabla }\end{array}$ & Salvator Rosa & diám.: 1 palmo y $1 / 2$ \\
\hline 6 & $\begin{array}{l}\text { Esponsales campestres, costumbre española, } \\
\text { lienzo }\end{array}$ & "Lonei" & diám.: 2 palmos \\
\hline 7 & 2 cuadros Paisaje con figuras, lienzo & Escuela de Poussin & $\begin{array}{l}\text { ancho: } 2 \text { palmos y } 1 / 8 \\
\text { alto: } 1 \text { palmo y } 1 / 4\end{array}$ \\
\hline 8 & 2 cuadros Paisaje, lienzo & Autor desconocido & $\begin{array}{l}\text { ancho: } 1 \text { palmo y } 1 / 2 \\
\text { alto: } 1 \text { palmo }\end{array}$ \\
\hline 9 & $\begin{array}{l}2 \text { cuadros Paisaje con figuras campestres, } \\
\text { lienzo }\end{array}$ & Escuela de Poussin & $\begin{array}{l}\text { ancho: } 2 \text { palmos y } 1 / 8 \\
\text { alto: } 1 \text { palmo y } 1 / 4\end{array}$ \\
\hline 10 & $\begin{array}{l}2 \text { cuadros Paisaje, lienzo, óvalo en la parte } \\
\text { inferior }\end{array}$ & João Baptista Bussirri & $\begin{array}{l}\text { ancho: } 2 \text { palmos } \\
\text { alto: } 1 \text { palmo y } 1 / 2\end{array}$ \\
\hline 11 & 2 cuadros Paisaje y figuras & $\begin{array}{l}\text { João Baptista Bussirri } \\
\text { (paisaje) y Placido } \\
\text { Constanzi (figuras) }\end{array}$ & $\begin{array}{l}\text { ancho: } 3 \text { palmos y } 1 / 4 \\
\text { alto: } 2 \text { palmos y } 1 / 4\end{array}$ \\
\hline 12 & $\begin{array}{l}\text { La caída de un rayo y dos pastores huyendo } \\
\text { precipitadamente con el ganado, lienzo }\end{array}$ & Nicolas Poussin & $\begin{array}{l}\text { ancho: } 6 \text { palmos y } 1 / 8 \\
\text { alto: } 3 \text { palmos y } 1 / 4\end{array}$ \\
\hline 13 & Figuras, fuente y lavanderas, lienzo & $\begin{array}{l}\text { Escuela de Nicolas } \\
\text { Poussin }\end{array}$ & $\begin{array}{l}\text { ancho: } 6 \text { palmos y } 1 / 8 \\
\text { alto: } 3 \text { palmos y } 1 / 4\end{array}$ \\
\hline 14 & $\begin{array}{l}\text { Las cascadas del Tívoli junto a Roma en } \\
1813 \text {, lienzo }\end{array}$ & "Mr. Alovres" & $\begin{array}{l}\text { ancho: } 4 \text { palmos y } 1 / 3 \\
\text { alto: } 3 \text { palmos }\end{array}$ \\
\hline 15 & Un bosque, lienzo & Autor desconocido & $\begin{array}{l}\text { ancho: } 6 \text { palmos } \\
\text { alto: } 3 \text { palmos }\end{array}$ \\
\hline 17 & El Rey Don Juan VI & Autor desconocido & $\begin{array}{l}\text { ancho: } 2 \text { palmos y } 7 / 8 \\
\text { alto: } 3 \text { palmos y } 1 / 3\end{array}$ \\
\hline 18 & $\begin{array}{l}2 \text { cuadros: Naufragio de un navío / Vista de } \\
\text { un puerto de mar, figuras comerciales y } \\
\text { pescadores, representando la elevación del } \\
\text { sol antepuesto a la neblina, lienzo }\end{array}$ & Horace Vernet ${ }^{46}$ & $\begin{array}{l}\text { ancho: } 6 \text { palmos y } 1 / 3 \\
\text { alto: } 3 \text { palmos y } 1 / 2\end{array}$ \\
\hline 19 & 2 cuadros paisaje marino nocturno, lienzo & Escuela francesa & $\begin{array}{l}\text { ancho: } 3 \text { palmos } \\
\text { alto: } 2 \text { palmos y } 1 / 8\end{array}$ \\
\hline 20 & $\begin{array}{l}2 \text { cuadros paisaje marino / elevación del sol } \\
\text { antepuesto a la neblina, lienzo }\end{array}$ & $\begin{array}{l}\text { L'Orizzonte [Jan } \\
\text { Frans van Bloemen] }\end{array}$ & $\begin{array}{l}\text { ancho: } 2 \text { palmos y } 7 / 8 \\
\text { alto: } 2 \text { palmos }\end{array}$ \\
\hline 21 & $\begin{array}{l}\text { Orfeo encantando a los animales con su } \\
\text { voz, lienzo }\end{array}$ & Brueghel & $\begin{array}{l}\text { ancho: } 2 \text { palmos y } 1 / 3 \\
\text { alto: } 1 \text { palmo y } 1 / 2\end{array}$ \\
\hline
\end{tabular}

46 Obras associadas al pintor Claude-Joseph Vernet. MNAA, Inv. 467 y 468 Pint. 


\begin{tabular}{|c|c|c|c|}
\hline $\mathbf{N}^{0}$ & Cuadros / Temas representados & Autoría/Atribución & Dimensiones \\
\hline 22 & $\begin{array}{l}\text { Un país y figuras de hechos históricos, Lot } \\
\text { y sus hijas, tabla }\end{array}$ & Autor desconocido & $\begin{array}{l}\text { ancho: } 1 \text { palmo y } 1 / 2 \\
\text { alto: } 1 \text { palmo }\end{array}$ \\
\hline 34 & Ulises y Héctor, lienzo & $\begin{array}{l}\text { Escuela de Paolo } \\
\text { Veronese }\end{array}$ & $\begin{array}{l}\text { ancho: } 4 \text { palmos } \\
\text { alto: } 2 \text { palmos }\end{array}$ \\
\hline 35 & Emperatriz alemana, lienzo & Bronzino $^{47}$ & $\begin{array}{l}\text { ancho: } 4 \text { palmos y } 1 / 3 \\
\text { alto: } 6 \text { palmos y } 1 / 8\end{array}$ \\
\hline 36 & Esclava, lienzo & Copia de Tiziano & $\begin{array}{l}\text { ancho: } 4 \text { palmos y } 1 / 4 \\
\text { alto: } 4 \text { palmos y } 2 / 3\end{array}$ \\
\hline 37 & Los dos hermanos, cuerpo entero, lienzo & Escuela veneciana & $\begin{array}{l}\text { ancho: } 4 \text { palmos y } 1 / 3 \\
\text { alto: } 6 \text { palmos y } 1 / 8\end{array}$ \\
\hline 38 & $\begin{array}{l}\text { Luis XVI, rey de Francia, cuerpo entero, } \\
\text { lienzo }\end{array}$ & Autor desconocido & $\begin{array}{l}\text { ancho: } 4 \text { palmos y } 1 / 3 \\
\text { alto: } 6 \text { palmos y } 1 / 4\end{array}$ \\
\hline 39 & Niña jugando con un perrito, lienzo & $\begin{array}{l}\text { Escuela de Raphael } \\
\text { Mengs }\end{array}$ & $\begin{array}{l}\text { ancho: } 4 \text { palmos } \\
\text { alto: } 2 \text { palmos y } 1 / 8\end{array}$ \\
\hline 40 & $\begin{array}{l}\text { Tres cuadros: muy comunes, que } \\
\text { representan las tres artes: Pintura, } \\
\text { Arquitectura y Escultura, lienzo }\end{array}$ & Autor desconocido & $\begin{array}{l}\text { ancho: } 4 \text { palmos } \\
\text { alto: } 5 \text { palmos y } 3 / 4\end{array}$ \\
\hline 41 & Fernando VII, lienzo & Autor desconocido & $\begin{array}{l}\text { ancho: } 4 \text { palmos y } 1 / 8 \\
\text { alto: } 5 \text { palmos y } 3 / 4\end{array}$ \\
\hline 49 & $\begin{array}{l}\text { Paisaje con vista de templo arruinado, } \\
\text { lienzo }\end{array}$ & João Terni & $\begin{array}{l}\text { ancho: } 1 \text { palmo y } 3 / 4 \\
\text { alto: } 1 \text { palmo y } 1 / 3\end{array}$ \\
\hline 50 & $\begin{array}{l}\text { Antiguo Campo de Vaccino de Roma con } \\
\text { grupos de figuras y ganado, lienzo }\end{array}$ & $\begin{array}{l}\text { [Pieter van Laer] } \\
\text { Bamboccio }\end{array}$ & $\begin{array}{l}\text { ancho: } 6 \text { palmos } \\
\text { alto: } 4 \text { palmos y } 1 / 4\end{array}$ \\
\hline 51 & Pastores y ganado, lienzo & $\begin{array}{l}\text { Escuela de Salvator } \\
\text { Rosa }\end{array}$ & $\begin{array}{l}\text { ancho: } 4 \text { palmos y } 7 / 8 \\
\text { alto: } 4 \text { palmos }\end{array}$ \\
\hline 52 & Ruinas de Roma, lienzo & $\begin{array}{l}\text { Discípulo de } \\
\text { Francisco Pannini }{ }^{48}\end{array}$ & $\begin{array}{l}\text { ancho: } 2 \text { palmos y } 3 / 4 \\
\text { alto: } 3 \text { palmos y } 1 / 3\end{array}$ \\
\hline 53 & Ruinas de Roma, lienzo & Pannini & $\begin{array}{l}\text { ancho: } 4 \text { palmos y } 1 / 2 \\
\text { alto: } 3 \text { palmos y } 1 / 2\end{array}$ \\
\hline 54 & $\begin{array}{l}\text { Frontispicio de un palacio, adornos de } \\
\text { concha y figuras, lienzo }\end{array}$ & Autor desconocido & $\begin{array}{l}\text { ancho: } 4 \text { palmos y } 1 / 3 \\
\text { alto: } 3 \text { palmos y } 1 / 3\end{array}$ \\
\hline 55 & $\begin{array}{l}\text { Cuatro cuadros: cestillos con flores y frutos, } \\
\text { con conchas en altorrelieve, con cajas y } \\
\text { vidrios, lienzo }\end{array}$ & Autor desconocido & $\begin{array}{l}\text { ancho: } 2 \text { palmos y } 1 / 2 \\
\text { alto: } 2 \text { palmos }\end{array}$ \\
\hline 58 & Seis cuadros: Historia Sacra, lienzo & $\begin{array}{l}\text { Copia de un discípulo } \\
\text { de Bassano }\end{array}$ & $\begin{array}{l}\text { ancho: } 1 \text { palmo y } 1 / 4 \\
\text { alto: } 1 \text { palmo }\end{array}$ \\
\hline 59 & Dos cuadros: Batallas de Bursardon, cobre & Autor desconocido & $\begin{array}{l}\text { ancho: } 1 \text { palmo y } 3 / 4 \\
\text { alto: } 1 \text { palmo y } 1 / 8\end{array}$ \\
\hline 60 & Dos cuadros: Batallas antiguas, cobre & $\begin{array}{l}\text { [Jacques Courtois] } \\
\text { Borgoñón }\end{array}$ & $\begin{array}{l}\text { ancho: } 2 \text { palmos y } 1 / 8 \\
\text { alto: } 1 \text { palmo y } 1 / 4\end{array}$ \\
\hline 61 & El botín de una batalla & $\begin{array}{l}\text { Discípulo del } \\
\text { Borgoñón }\end{array}$ & $\begin{array}{l}\text { ancho: } 2 \text { palmos } \\
\text { alto: } 1 \text { palmo y } 1 / 3\end{array}$ \\
\hline 62 & $\begin{array}{l}\text { Nuestra Señora con el Niño Jesús, oval, } \\
\text { lienzo }\end{array}$ & $\begin{array}{l}\text { Copia de Giulio } \\
\text { Romano }\end{array}$ & $\begin{array}{l}\text { ancho: } 4 \text { palmos } \\
\text { alto: } 5 \text { palmos y } 1 / 3\end{array}$ \\
\hline
\end{tabular}

${ }^{47}$ Identificada más tarde como obra de Jacopo Ligozzi, se cree que representa a María de Médici (MNAA, Inv. 453 Pint.). Xavier, 2018: 75.

48 Se trata, muy probablemente, de Giovanni Paolo Pannini. 


\begin{tabular}{|c|c|c|c|}
\hline $\mathbf{N}^{\circ}$ & Cuadros / Temas representados & Autoría/Atribución & Dimensiones \\
\hline 63 & La Paciencia, cuerpo entero, tabla & $\begin{array}{l}\text { Perino del Vaga, } \\
\text { discípulo de Rafael }\end{array}$ & $\begin{array}{l}\text { ancho: } 4 \text { palmos e } 3 / 4 \\
\text { alto: } 3 \text { palmos y } 3 / 4\end{array}$ \\
\hline 64 & $\begin{array}{l}\text { Judith tras cortarle la cabeza a Holofernes, } \\
\text { figura colosal, lienzo }\end{array}$ & Guido Reni & $\begin{array}{l}\text { ancho: } 6 \text { palmos y } 1 / 2 \\
\text { alto: } 9 \text { palmos y } 3 / 4\end{array}$ \\
\hline 65 & $\begin{array}{l}\text { Herodes con la cabeza del Bautista, medio } \\
\text { cuerpo natural, lienzo }\end{array}$ & $\begin{array}{l}\text { Polidoro de } \\
\text { Caravaggio }\end{array}$ & $\begin{array}{l}\text { ancho: } 3 \text { palmos y } 1 / 2 \\
\text { alto: } 4 \text { palmos y } 3 / 4\end{array}$ \\
\hline 66 & $\begin{array}{l}\text { Nuestra Señora con el Niño durmiendo, } \\
\text { oval, lienzo }\end{array}$ & $\begin{array}{l}\text { Copia antigua de } \\
\text { Guido Reni }\end{array}$ & $\begin{array}{l}\text { ancho: } 5 \text { palmos y } 3 / 4 \\
\text { alto: } 4 \text { palmos }\end{array}$ \\
\hline 67 & $\begin{array}{l}\text { Martirio de un obispo, figuras al natural, } \\
\text { amanerado, lienzo }\end{array}$ & $\begin{array}{l}\text { "Primera manera" de } \\
\text { Rubens }{ }^{49}\end{array}$ & $\begin{array}{l}\text { ancho: } 8 \text { palmos y } 2 / 3 \\
\text { alto: } 13 \text { palmos y } 3 / 4\end{array}$ \\
\hline 68 & San Sebastián Mártir, lienzo & $\begin{array}{l}\text { Copia hecha por } \\
\text { Máximo Vicente }\end{array}$ & $\begin{array}{l}\text { ancho: } 4 \text { palmos y } 1 / 3 \\
\text { alto: } 9 \text { palmos }\end{array}$ \\
\hline 69 & $\begin{array}{l}\text { Arzobispo de Valencia Juan de Ribera } \\
\text { predicando a los gentiles }\end{array}$ & Giuseppe Cades & $\begin{array}{l}\text { ancho: } 8 \text { palmos y } 2 / 3 \\
\text { alto: } 3 \text { palmos y } 3 / 4\end{array}$ \\
\hline 70 & Martirio de San Pedro Apóstol & $\begin{array}{l}\text { Copia de Annibale } \\
\text { Carracci realizada } \\
\text { por Polidoro de } \\
\text { Caravaggio }\end{array}$ & $\begin{array}{l}\text { ancho: } 7 \text { palmos y } 3 / 4 \\
\text { alto: } 10 \text { palmos y } 1 / 2\end{array}$ \\
\hline 71 & Bautismo de San Hermenegildo, lienzo & $\begin{array}{l}\text { Original de Guercino } \\
\text { da Cento }\end{array}$ & $\begin{array}{l}\text { ancho: } 8 \text { palmos } \\
\text { alto: } 10 \text { palmos y } 2 / 3\end{array}$ \\
\hline 74 & Marina con figuritas, lienzo & Escuela flamenca & $\begin{array}{l}\text { ancho: } 5 \text { palmos } \\
\text { alto: } 4 \text { palmos y } 1 / 3\end{array}$ \\
\hline 75 & País rústico, lienzo & $\begin{array}{l}\text { Escuela de Salvator } \\
\text { Rosa }\end{array}$ & $\begin{array}{l}\text { ancho: } 6 \text { palmos } \\
\text { alto: } 4 \text { palmos y } 1 / 4\end{array}$ \\
\hline 76 & $\begin{array}{l}\text { Jesucristo cuando dice al profano que deje } \\
\text { el comercio y lo acompañe, lienzo }\end{array}$ & M. Valentin & $\begin{array}{l}\text { ancho: } 10 \text { palmos } \\
\text { alto: } 7 \text { palmos y } 3 / 4\end{array}$ \\
\hline 77 & $\begin{array}{l}\text { Aparición del descendimiento de la cruz a } \\
\text { San Francisco, figuras al natural, lienzo }\end{array}$ & $\begin{array}{l}\text { Original de Guercino } \\
\text { de su última manera } \\
{ }^{50}\end{array}$ & $\begin{array}{l}\text { ancho: } 11 \text { palmos y } \\
1 / 2 \\
\text { alto: } 8 \text { palmos }\end{array}$ \\
\hline 78 & Perspectiva de un palacio con figuras, lienzo & $\begin{array}{l}\text { Original de } \\
\text { Bamboccio }\end{array}$ & $\begin{array}{l}\text { ancho: } 5 \text { palmos y } 2 / 3 \\
\text { alto: } 4 \text { palmos y } 1 / 8\end{array}$ \\
\hline 79 & Adán, Eva, Caín y Abel, lienzo & Original de Palma & $\begin{array}{l}\text { ancho: } 9 \text { palmos } \\
\text { alto: } 6 \text { palmos y } 1 / 2\end{array}$ \\
\hline 80 & Magdalena en el desierto, media figura & Autor desconocido & $\begin{array}{l}\text { ancho: } 4 \text { palmos y } 1 / 2 \\
\text { alto: } 5 \text { palmos }\end{array}$ \\
\hline 81 & $\begin{array}{l}\text { Mujer adúltera presentada a Jesucristo, } \\
\text { media figura, lienzo }\end{array}$ & $\begin{array}{l}\text { Original de la manera } \\
\text { suelta de Tiziano }\end{array}$ & $\begin{array}{l}\text { ancho: } 7 \text { palmos y } 1 / 8 \\
\text { alto: } 4 \text { palmos y } 1 / 2\end{array}$ \\
\hline 82 & Bambochada, tabla & $\begin{array}{l}\text { Copia de David } \\
\text { Teniers }\end{array}$ & $\begin{array}{l}\text { ancho: } 1 \text { palmo y } 1 / 2 \\
\text { alto: } 1 \text { palmo y } 1 / 4\end{array}$ \\
\hline 83 & Paisaje, tabla & Escuela de Teniers & $\begin{array}{l}\text { ancho: } 2 \text { palmos y } 1 / 8 \\
\text { alto: } 1 \text { palmo y } 1 / 2\end{array}$ \\
\hline 84 & $\begin{array}{l}\text { Vista de la iglesia de San Francisco de } \\
\text { Roma, lienzo }\end{array}$ & Escuela Romana & $\begin{array}{l}\text { ancho: } 2 \text { palmos y } 1 / 8 \\
\text { alto: } 1 \text { palmo y } 2 / 3\end{array}$ \\
\hline 85 & $\begin{array}{l}\text { Paisaje, Abel y Caín luchando con las fieras, } \\
\text { lienzo }\end{array}$ & Palma & $\begin{array}{l}\text { larg: } 10 \text { palmos y } 1 / 4 \\
\text { alto: } 7 \text { palmos y } 3 / 4\end{array}$ \\
\hline
\end{tabular}

49 Identificado como Martirio de San Policarpo, MNAA, Inv. 457 Pint.

${ }^{50}$ Luca Giordano, Éxtasis de San Francisco, MNAA, Inv. 719 Pint [fig. 4]. 


\begin{tabular}{|c|c|c|c|}
\hline $\mathbf{N}^{\circ}$ & Cuadros / Temas representados & Autoría/Atribución & Dimensiones \\
\hline 86 & $\begin{array}{l}\text { Nuestra Señora con el Niño Jesús y dos } \\
\text { Ángeles, lienzo }\end{array}$ & $\begin{array}{l}\text { Copia de la parte } \\
\text { superior de un cuadro } \\
\text { de Tiziano que existe } \\
\text { en la Galería } \\
\text { Vaticana }\end{array}$ & $\begin{array}{l}\text { ancho: } 8 \text { palmos } \\
\text { alto: } 6 \text { palmos }\end{array}$ \\
\hline 94 & Botellas, vasos y flores, lienzo & Autor desconocido & $\begin{array}{l}\text { ancho: } 2 \text { palmos } \\
\text { alto: } 2 \text { palmos y } 1 / 8\end{array}$ \\
\hline 95 & $\begin{array}{l}\text { Dos cuadros: Un Químico / Accesorios de } \\
\text { cocina, lienzo }\end{array}$ & Autor desconocido & $\begin{array}{l}\text { ancho: } 3 \text { palmos } \\
\text { alto: } 2 \text { palmos y } 1 / 2\end{array}$ \\
\hline 96 & $\begin{array}{l}\text { Copa con vino, setas y rábanos con un } \\
\text { cuchillo metido en perspectiva, lienzo }\end{array}$ & Jorge Akactrit, 1664 & $\begin{array}{l}\text { ancho: } 2 \text { palmos y } 2 / 3 \\
\text { alto: } 2 \text { palmos y } 1 / 4\end{array}$ \\
\hline 97 & $\begin{array}{l}\text { Dos cuadros: Fruteros con diversos } \\
\text { utensilios, lienzo }\end{array}$ & Pereda & $\begin{array}{l}\text { ancho: } 6 \text { palmos y } 2 / 3 \\
\text { alto: } 3 \text { palmos y } 1 / 4\end{array}$ \\
\hline 98 & $\begin{array}{l}\text { Venus en el tocador, con diversos } \\
\text { cuadros, objetos de arte, joyas y otras } \\
\text { preciosidades }\end{array}$ & Brueghel & $\begin{array}{l}\text { ancho: } 4 \text { palmos } \\
\text { alto: } 2 \text { palmos y } 3 / 4\end{array}$ \\
\hline 99 & $\begin{array}{l}\text { Dos cuadros: Acueducto de las Aguas } \\
\text { Libres / Entrada de la barra de Lisboa, } \\
\text { lienzo }\end{array}$ & Pillement & $\begin{array}{l}\text { ancho: } 4 \text { palmos } \\
\text { alto: } 2 \text { palmos y } 3 / 4\end{array}$ \\
\hline 103 & Cena de los macacos, tabla & David Teniers & Pequeño \\
\hline 104 & Tres cuadros: Países, lienzo & Escuela flamenca & $\begin{array}{l}\text { ancho: } 1 \text { palmo y } 1 / 4 \\
\text { alto: } 2 / 3 \text { palmo }\end{array}$ \\
\hline 105 & Paisaje, cobre & Escuela de Paul Brill & $\begin{array}{l}\text { ancho: } 1 \text { palmo } \\
\text { alto: } 3 / 4 \text { palmo }\end{array}$ \\
\hline 106 & 3 cuadros de paisajes & D. Félix Terres & Sin medidas \\
\hline 107 & Marina, circular & Autor desconocido & diám.:1/2 palmo \\
\hline 108 & Paisaje & Autor desconocido & $\begin{array}{l}\text { ancho: } 1 \text { palmo y } 1 / 4 \\
\text { alto: } 1 / 2 \text { palmo }\end{array}$ \\
\hline 110 & $\begin{array}{l}\text { Nuestra Señora y el Niño sentado en una } \\
\text { silla antigua con San Miguel y San José } \\
\text { y pequeña Gloria en la parte superior, } \\
\text { tabla }\end{array}$ & $\begin{array}{l}\text { "Sublime" fragmento } \\
\text { de Rafael Urbino }\end{array}$ & Sin medidas \\
\hline 111 & San Jerónimo en el desierto, lienzo & M. Valentin & $\begin{array}{l}\text { ancho: } 7 \text { palmos } \\
\text { alto: } 5 \text { palmos }\end{array}$ \\
\hline 112 & Desposorio de Santa Catalina, lienzo & Escuela romana & $\begin{array}{l}\text { ancho: } 7 \text { palmos } \\
\text { alto: } 6 \text { palmos y } 1 / 4\end{array}$ \\
\hline 113 & Natividad de Nuestra Señora, lienzo & $\begin{array}{l}\text { Copia de un cuadro } \\
\text { de Escuela romana }\end{array}$ & $\begin{array}{l}\text { ancho: } 8 \text { palmos y } 1 / 2 \\
\text { alto: } 9 \text { palmos }\end{array}$ \\
\hline 114 & Paisaje ("muy mediocre"), lienzo & Autor desconocido & $\begin{array}{l}\text { ancho: } 9 \text { palmos } \\
\text { alto: } 8 \text { palmos y } 3 / 4\end{array}$ \\
\hline 115 & Paisajes y flores, lienzo & "Autor mediocre" & $\begin{array}{l}\text { ancho: } 6 \text { palmos y } 3 / 4 \\
\text { alto: } 5 \text { palmos }\end{array}$ \\
\hline 116 & Nuestra Señora con el Niño, lienzo & $\begin{array}{l}\text { Copia de Escuela } \\
\text { romana }\end{array}$ & $\begin{array}{l}\text { ancho: } 4 \text { palmos y } 1 / 2 \\
\text { alto: } 6 \text { palmos }\end{array}$ \\
\hline 117 & Adoración de los Pastores, circular, tabla & $\begin{array}{l}\text { Primera manera de } \\
\text { Rafael }\end{array}$ & diám.: 3 palmos y $1 / 2$ \\
\hline 118 & Apolo, media figura colosal, lienzo & $\begin{array}{l}\text { Original de } \\
\text { Domenichino }\end{array}$ & $\begin{array}{l}\text { ancho: } 2 \text { palmos y } 1 / 2 \\
\text { alto: } 4 \text { palmos }\end{array}$ \\
\hline
\end{tabular}




\begin{tabular}{|c|c|c|c|}
\hline $\mathbf{N}^{\circ}$ & Cuadros / Temas representados & Autoría/Atribución & Dimensiones \\
\hline 119 & $\begin{array}{l}\text { Abraham ofreciendo la cena a } 3 \text { ángeles, } \\
\text { lienzo }\end{array}$ & Ugo da Capri & $\begin{array}{l}\text { ancho: } 3 \text { palmos y } 1 / 2 \\
\text { alto: sem medida }\end{array}$ \\
\hline 120 & Marinas, lienzo & Copia de Vernet & $\begin{array}{l}\text { ancho: } 5 \text { palmos y } 1 / 3 \\
\text { alto: } 2 \text { palmos }\end{array}$ \\
\hline 121 & Campesino gritando, lienzo & Copia de Caravaggio & $\begin{array}{l}\text { ancho: } 2 \text { palmos } \\
\text { alto: } 2 \text { palmos y } 2 / 3\end{array}$ \\
\hline 122 & Baco, lienzo & $\begin{array}{l}\text { Escuela de Nicolas } \\
\text { Poussin }\end{array}$ & $\begin{array}{l}\text { ancho: } 3 \text { palmos y } 3 / 4 \\
\text { alto: } 4 \text { palmos y } 1 / 3\end{array}$ \\
\hline 123 & Dos cabezas de apóstoles, lienzo & Copia de Guercino & $\begin{array}{l}\text { ancho: } 2 \text { palmos y } 1 / 2 \\
\text { alto: } 2 \text { palmos }\end{array}$ \\
\hline 124 & $\begin{array}{l}\text { Un viejo y una vieja lacrando una carta, } \\
\text { lienzo }\end{array}$ & Escuela flamenca & $\begin{array}{l}\text { ancho: } 3 \text { palmos y } 1 / 4 \\
\text { alto: } 4 \text { palmos y } 1 / 3\end{array}$ \\
\hline 125 & Media figura, lienzo & Autor desconocido & $\begin{array}{l}\text { ancho: } 2 \text { palmos } \\
\text { alto: } 3 \text { palmos }\end{array}$ \\
\hline 126 & San Andrés, media figura, lienzo & Autor desconocido & $\begin{array}{l}\text { ancho: } 2 \text { palmos } \\
\text { alto: } 3 \text { palmos }\end{array}$ \\
\hline 127 & $\begin{array}{l}\text { Nuestra Señora con el Niño Jesús } \\
\text { durmiendo, lienzo }\end{array}$ & Copia de Sassoferrato & $\begin{array}{l}\text { ancho: } 1 \text { palmo y } 1 / 2 \\
\text { alto: sin medida }\end{array}$ \\
\hline 128 & $\begin{array}{l}\text { Jesucristo en la tumba con tres apóstoles } \\
\text { que ayudan a ponerlo en el sepulcro, figura } \\
\text { entera, tabla }\end{array}$ & Escuela veneciana & $\begin{array}{l}\text { ancho: } 7 \text { palmos y } 1 / 8 \\
\text { alto: } 3 \text { palmos y } 1 / 3\end{array}$ \\
\hline 129 & $\begin{array}{l}\text { Jesucristo en brazos del Padre Eterno, } \\
\text { simbolizando la Santísima Trinidad, lienzo }\end{array}$ & Ribera & $\begin{array}{l}\text { ancho: } 6 \text { palmos } \\
\text { alto: } 9 \text { palmos y } 2 / 3\end{array}$ \\
\hline 130 & Nuestro Señor Jesucristo crucificado, lienzo & Copia de Guido Reni & $\begin{array}{l}\text { ancho: } 6 \text { palmos } \\
\text { alto: sin medida }\end{array}$ \\
\hline 131 & Calvario, cobre & Discípulo de Rubens & $\begin{array}{l}\text { ancho: } 3 \text { palmos } \\
\text { alto: } 2 \text { palmos y } 1 / 4\end{array}$ \\
\hline 132 & $\begin{array}{l}\text { Un convento y la tentación de un ermitaño, } \\
\text { lienzo }\end{array}$ & Escuela flamenca & $\begin{array}{l}\text { ancho: } 1 \text { palmo y } 1 / 2 \\
\text { alto: } 1 / 2 \text { palmo }\end{array}$ \\
\hline 133 & $\begin{array}{l}\text { Dos cuadros: Adoración de los Reyes } \\
\text { Magos / Adoración de los Ángeles al Niño } \\
\text { Jesús y huida a Egipto, "figura gothica" } \\
\text { tabla }\end{array}$ & Lucas van Leyden & $\begin{array}{l}\text { ancho: } 2 \text { palmos y } 1 / 3 \\
\text { alto: } 4 \text { palmos }\end{array}$ \\
\hline 134 & Paisaje, tabla & $\begin{array}{l}\text { Copia de David } \\
\text { Teniers }\end{array}$ & $\begin{array}{l}\text { ancho: } 2 \text { palmos } \\
\text { alto: } 1 \text { palmo y } 1 / 2\end{array}$ \\
\hline 135 & Creación del Mundo, Adán y Eva, cobre & Original de Brueghel & $\begin{array}{l}\text { ancho: } 1 \text { palmo y } 1 / 4 \\
\text { alto: } 3 / 4 \text { palmo }\end{array}$ \\
\hline 138 & $\begin{array}{l}\text { Cabeza de San Juan Bautista presentada por } \\
\text { la mujer de Herodes, cobre }\end{array}$ & Copia de Rubens & $\begin{array}{l}\text { ancho: } 4 \text { palmos } \\
\text { alto: } 3 \text { palmos y } 1 / 8\end{array}$ \\
\hline 139 & $\begin{array}{l}\text { Nuestra Señora de la Concepción, el Padre } \\
\text { Eterno y Ángeles, lienzo }\end{array}$ & Conca & $\begin{array}{l}\text { ancho: } 2 \text { palmos } \\
\text { alto: } 3 \text { palmos y } 1 / 2\end{array}$ \\
\hline 140 & Sagrada Familia, cartón & Parmigianino & $\begin{array}{l}\text { ancho: } 1 \text { palmo y } 3 / 4 \\
\text { alto: } 1 \text { palmo y } 1 / 3\end{array}$ \\
\hline 141 & Cristo en el Huerto, lienzo & Copia de Correggio & $\begin{array}{l}\text { ancho: } 1 \text { palmo y } 1 / 4 \\
\text { alto: } 1 \text { palmo }\end{array}$ \\
\hline 142 & $\begin{array}{l}\text { S. Carlos Borromeo y S. Felipe leyendo el } \\
\text { Oficio Divino, cartón }\end{array}$ & Autor desconocido & $\begin{array}{l}\text { ancho: } 1 \text { palmo } \\
\text { alto: } 3 / 4 \text { palmo }\end{array}$ \\
\hline 143 & Nuestra Señora orando, media figura & Autor desconocido & $\begin{array}{l}\text { ancho: } 1 \text { palmo } \\
\text { alto: } 1 / 2 \text { palmo }\end{array}$ \\
\hline
\end{tabular}




\begin{tabular}{|c|c|c|c|}
\hline $\mathbf{N}^{0}$ & Cuadros / Temas representados & Autoría/Atribución & Dimensiones \\
\hline 144 & $\begin{array}{l}\text { Nuestra Señora y el Niño Jesús en pie, } \\
\text { lienzo }\end{array}$ & $\begin{array}{l}\text { Copia de Maratta } \\
\text { hecha por Trono }\end{array}$ & $\begin{array}{l}\text { ancho: } 1 \text { palmo y } 1 / 2 \\
\text { alto: } 2 \text { palmos }\end{array}$ \\
\hline 145 & Presentación en el Templo & Boceto de Murillo & $\begin{array}{l}\text { ancho: } 1 \text { palmo y } 1 / 3 \\
\text { alto: } 2 \text { palmos y } 3 / 4\end{array}$ \\
\hline 146 & $\begin{array}{l}\text { Nuestra Señora y el Niño apareciendo a los } \\
\text { Santos Mártires, cobre }\end{array}$ & Escuela flamenca & $\begin{array}{l}\text { ancho: } 1 \text { palmo y } 1 / 4 \\
\text { alto: } 2 \text { palmos y } 1 / 4\end{array}$ \\
\hline 147 & $\begin{array}{l}\text { Retrato del eminente cardenal patriarca, } \\
\text { Patricio I, lienzo }\end{array}$ & Autor desconocido & $\begin{array}{l}\text { ancho: } 2 \text { palmo } 2 \text { y } 1 / 3 \\
\text { alto: } 1 \text { palmo y } 2 / 3\end{array}$ \\
\hline 148 & Nuestra Señora, lienzo & Autor desconocido & $\begin{array}{l}\text { ancho: } 1 \text { palmo } \\
\text { alto: } 1 \text { palmo y } 2 / 3\end{array}$ \\
\hline 149 & La Verónica del Señor, lienzo & $\begin{array}{l}\text { Copia de Pompeo } \\
\text { Batoni }\end{array}$ & $\begin{array}{l}\text { ancho: } 1 \text { palmo y } 2 / 3 \\
\text { alto: } 2 \text { palmos y } 1 / 3\end{array}$ \\
\hline 150 & Éxtasis de San Francisco y Ángeles, cobre & Original de Sequeira & $\begin{array}{l}\text { ancho: } 1 \text { palmo y } 1 / 3 \\
\text { alto: } 2 \text { palmos y } 1 / 3\end{array}$ \\
\hline 151 & Señor de la Caña Verde, lienzo & $\begin{array}{l}\text { Copia de Guido Reni, } \\
\text { por la escuela de } \\
\text { Pedro Alexandrino }\end{array}$ & $\begin{array}{l}\text { ancho: } 1 \text { palmo y } 1 / 2 \\
\text { alto: } 2 \text { palmos }\end{array}$ \\
\hline 152 & $\begin{array}{l}\text { San Francisco orando en el desierto, pintado } \\
\text { sobre mármol oriental }\end{array}$ & Autor desconocido & $\begin{array}{l}\text { ancho: } 3 / 4 \text { palmo } \\
\text { alto: } 1 \text { palmo }\end{array}$ \\
\hline 153 & $\begin{array}{l}\text { Cinco cuadros: La Verónica del Señor / } \\
\text { Señor Jesús de los Pasos / San Francisco / } \\
\text { San Simón / San Pedro }\end{array}$ & Autor desconocido & Sin medidas \\
\hline 154 & $\begin{array}{l}\text { Nuestra Señora con las Vírgenes, cuadro en } \\
\text { miniatura pintado sobre pergamino }\end{array}$ & Autor desconocido & Sin medidas \\
\hline 163 & $\begin{array}{l}\text { Nuestra Señora de la Encarnación, oval, } \\
\text { media figura, tabla }\end{array}$ & $\begin{array}{l}\text { Original de Guido } \\
\text { Reni }\end{array}$ & 2 palmos y $3 / 4$ \\
\hline 164 & $\begin{array}{l}\text { Jesucristo con la Cruz a la espalda, media } \\
\text { figura }\end{array}$ & Original de Luini & $\begin{array}{l}\text { ancho: } 2 \text { palmos y } 1 / 4 \\
\text { alto: } 2 \text { palmos y } 3 / 4\end{array}$ \\
\hline 165 & San Felipe Apóstol, lienzo & Original de Velásquez & $\begin{array}{l}\text { ancho: } 1 \text { palmo y } 3 / 4 \\
\text { alto: } 2 \text { palmos y } 1 / 4\end{array}$ \\
\hline 166 & Un Apóstol, lienzo & $\begin{array}{l}\text { Copia de Annibale } \\
\text { Carracci }\end{array}$ & $\begin{array}{l}\text { ancho: } 2 \text { palmos y } 1 / 4 \\
\text { alto: } 3 \text { palmos }\end{array}$ \\
\hline 167 & San Pedro, lienzo & Autor desconocido & $\begin{array}{l}\text { ancho: } 2 \text { palmos y } 1 / 2 \\
\text { alto: } 3 \text { palmos }\end{array}$ \\
\hline 168 & $\begin{array}{l}\text { Desposorios místicos de Santa Catalina y } \\
\text { San Jerónimo, tabla }\end{array}$ & $\begin{array}{l}\text { Original de } \\
\text { Parmigianino }\end{array}$ & $\begin{array}{l}\text { ancho: } 2 \text { palmos y } 1 / 4 \\
\text { alto: } 2 \text { palmos }\end{array}$ \\
\hline 169 & San Francisco recibiendo los estigmas, tabla & Copia de Cigoli & $\begin{array}{l}\text { ancho: } 1 \text { palmo y } 3 / 4 \\
\text { alto: } 2 \text { palmos }\end{array}$ \\
\hline 170 & San Jerónimo orando, media figura, lienzo & $\begin{array}{l}\text { Original de El } \\
\text { Españoleto }\end{array}$ & $\begin{array}{l}\text { ancho: } 3 \text { palmos } \\
\text { alto: } 4 \text { palmos y } 1 / 4\end{array}$ \\
\hline 171 & $\begin{array}{l}\text { San Jerónimo orando, media figura colosal, } \\
\text { lienzo }\end{array}$ & $\begin{array}{l}\text { Original de } \\
\text { Lanfranco }\end{array}$ & $\begin{array}{l}\text { ancho: } 4 \text { palmos } \\
\text { alto: } 5 \text { palmos y } 3 / 4\end{array}$ \\
\hline 172 & $\begin{array}{l}\text { Nuestra Señora y el Niño Jesús de la Rosa, } \\
\text { lienzo }\end{array}$ & Copia de Correggio & $\begin{array}{l}\text { ancho: } 4 \text { palmos } \\
\text { alto: } 5 \text { palmos y } 3 / 4\end{array}$ \\
\hline 173 & Nuestra Señora y el Niño Jesús, lienzo & $\begin{array}{l}\text { Copia de Rosso } \\
\text { Florentino }\end{array}$ & $\begin{array}{l}\text { ancho: } 3 \text { palmos y } 1 / 4 \\
\text { alto: } 4 \text { palmos }\end{array}$ \\
\hline 174 & $\begin{array}{l}\text { Nuestra Señora de la Soledad, figura oval, } \\
\text { lienzo }\end{array}$ & Copia de Carlo Dolci & $\begin{array}{l}\text { ancho: } 2 \text { palmos } \\
\text { alto: } 2 \text { palmos y } 3 / 4\end{array}$ \\
\hline
\end{tabular}




\begin{tabular}{|c|c|c|c|}
\hline $\mathbf{N}^{0}$ & Cuadros / Temas representados & Autoría/Atribución & Dimensiones \\
\hline 175 & Sagrada Familia y San Francisco, tabla & $\begin{array}{l}\text { "Sublime y primera } \\
\text { manera" de Rafael"15 }\end{array}$ & $\begin{array}{l}\text { ancho: } 2 \text { palmos } \\
\text { alto: } 1 \text { palmo y } 1 / 2\end{array}$ \\
\hline 176 & $\begin{array}{l}\text { Un rey de Judea amonestado por un profeta, } \\
\text { lienzo }\end{array}$ & $\begin{array}{l}\text { Esbozo de Pietro da } \\
\text { Cortona }\end{array}$ & $\begin{array}{l}\text { ancho: } 1 \text { palmo y } 1 / 4 \\
\text { alto: sin medida }\end{array}$ \\
\hline 177 & Sagrada Familia, lienzo & $\begin{array}{l}\text { Copia del tiempo de } \\
\text { Franciabigio }\end{array}$ & $\begin{array}{l}\text { ancho: } 3 \text { palmos y } 1 / 2 \\
\text { alto: } 5 \text { palmos }\end{array}$ \\
\hline 178 & $\begin{array}{l}\text { Jesucristo con la caña verde en el Pretorio de } \\
\text { Pilatos, presentado al pueblo por este, lienzo }\end{array}$ & $\begin{array}{l}\text { Original de } \\
\text { Sebastiano del } \\
\text { Piombo }\end{array}$ & $\begin{array}{l}\text { ancho: } 4 \text { palmos } \\
\text { alto: } 4 \text { palmos y } 1 / 2\end{array}$ \\
\hline 179 & Sagrada Familia, lienzo & Copia de Rafael & $\begin{array}{l}\text { ancho: } 3 \text { palmos y } 3 / 4 \\
\text { alto: } 5 \text { palmos }\end{array}$ \\
\hline 180 & Calvario, tabla & Escuela de Rubens & $\begin{array}{l}\text { ancho: } 2 \text { palmos } \\
\text { alto: } 3 \text { palmos }\end{array}$ \\
\hline 181 & Jesucristo presentado a Caifás, lienzo & Lucas van Leyden & $\begin{array}{l}\text { ancho: } 1 \text { palmo y } 3 / 4 \\
\text { alto: } 2 \text { palmos }\end{array}$ \\
\hline 182 & $\begin{array}{l}\text { Señor Jesús de los Pasos, media figura, } \\
\text { lienzo }\end{array}$ & Copia & $\begin{array}{l}\text { ancho: } 2 \text { palmos } \\
\text { alto: } 2 \text { palmos y } 1 / 2\end{array}$ \\
\hline 183 & San Jerónimo en el desierto, lienzo & $\begin{array}{l}\text { Escuela napolitana, } \\
\text { copia }\end{array}$ & $\begin{array}{l}\text { ancho: } 3 \text { palmos y } 1 / 4 \\
\text { alto: sin medida }\end{array}$ \\
\hline 184 & Magdalena en el desierto y paisaje & Escuela napolitana & $\begin{array}{l}\text { ancho: } 4 \text { palmos } \\
\text { alto: } 5 \text { palmos }\end{array}$ \\
\hline 185 & $\begin{array}{l}\text { San Francisco recibiendo los estigmas, } \\
\text { lienzo }\end{array}$ & Esbozo de Tiziano & $\begin{array}{l}\text { ancho: } 2 \text { palmos y } 3 / 4 \\
\text { alto: } 3 \text { palmos y } 1 / 4\end{array}$ \\
\hline 186 & Nuestra Señora de la silla, figura redonda & Copia de Rafael & Sin medidas \\
\hline 189 & $\begin{array}{l}\text { Dos cuadros: Adoración del Niño / El } \\
\text { pueblo de Israel recibiendo el maná, lienzo }\end{array}$ & $\begin{array}{l}\text { Original de } \\
\text { Pinturicchio, escuela } \\
\text { de Rafael / Escuela } \\
\text { romana }\end{array}$ & $\begin{array}{l}\text { ancho: } 3 \text { palmos y } 1 / 2 \\
\text { alto: } 4 \text { palmos }\end{array}$ \\
\hline 190 & $\begin{array}{l}\text { Dos cuadros: La muerte de Abel (temple) / } \\
\text { Abraham expulsando de casa a Agar }\end{array}$ & $\begin{array}{l}\text { Escuela de un pintor } \\
\text { romano moderno }\end{array}$ & Sin medidas \\
\hline 191 & Arcángel San Miguel, figura colosal & Copia de Guido Reni & Sin medidas \\
\hline 195 & San Juan, media figura, lienzo & $\begin{array}{l}\text { Copia antigua, } \\
\text { escuela de Rafael }\end{array}$ & $\begin{array}{l}\text { ancho: } 2 \text { palmos y } 1 / 4 \\
\text { alto: } 3 \text { palmos }\end{array}$ \\
\hline
\end{tabular}

A juzgar por su mínima representación en los inventarios, la escultura no parece haber ocupado un lugar muy destacado en las colecciones de la reina Carlota Joaquina. Con todo, habría que mencionar la existencia de al menos doce piezas de gran calidad artística: una escultura de mármol de bulto redondo, Magdalena en el desierto, considerada original de "Besuino" (muy probablemente Bernino) ${ }^{52}$; dos altares de mármol blanco de Italia, alusivos a San Francisco en el desierto y a Santa Teresa de Jesús; un altorrelieve de mármol, de forma oval, con el tema de la Adoración de los ángeles al cuerpo muerto de Jesús, del que se dice que "parece ser original de Bernini", con marco dorado [fig. 7]; Dos niños en mármol blanco, "copia de escultura antigua"; una escultura en mármol blanco representando a Una Vestal, considerada "original anti-

51 Actualmente atribuida a Ludovico Mazzolino, MNAA, Inv. 460 Pint. [fig. 3]. Xavier, 2018: 75. Tal vez se trate del cuadro n. ${ }^{\circ} 108$ del inventario de la pinacoteca de Carlos IV, referido por García-Frías, 2011: 219, nota 37. Cf. Bastos, 2014: 31 , nota 54 .

52 A la sazón era común referirse al artista italiano Bernini como Bernino. Lo más probable es que "Besuino" sea el resultado de un error tipográfico, pues no se conoce ningún escultor con ese apellido. 
Fig. 7. Autor desconocido, Descendimiento de la cruz con tres ángeles, ss. XVII-XVIII, 94,5 x 116 x 10,5 cm. MNAA, Inv.

41 Esc. Foto José Pessoa, 1995 CDGPC/ADF.

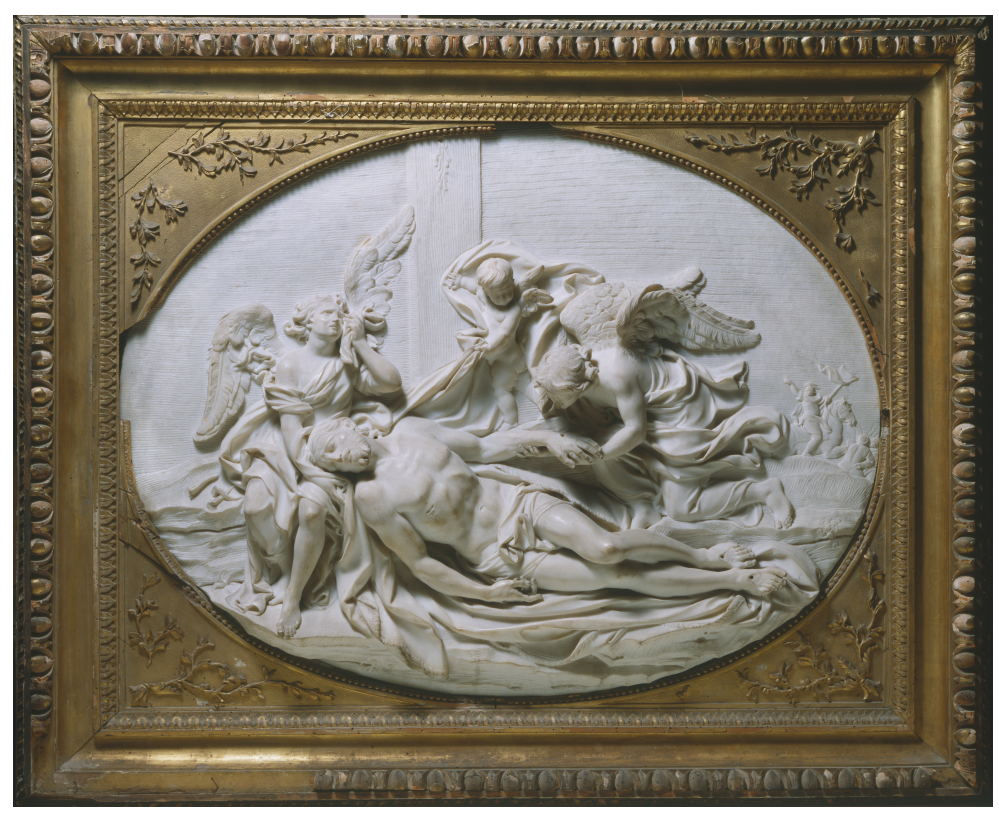

guo"; y 4 estatuas de mármol de Italia, alusivas a las cuatro estaciones del año. A lo que habría que añadir un cuadro "pintado en mármol oriental" representando a San Francisco orando en el desierto, con marco dorado y vidrio ${ }^{53}$ y dos figuras "de palmo y tres cuartos de altura, de cuerpo entero, casi desnudas, de carácter egipcio, en piedra roja, sobre bases de alabastro, de figura oval, con plintos cuadrilongos de granito rojo".

Otros objetos decorativos presentes en el inventario que estamos analizando también merecen una mención especial: dos vasos "al gusto borruminesco", con figuras en jaspe; dos globos terráqueos; un "palacio al estilo chino" hecho en marfil tallado, con su maquinilla; dos embarcaciones de "marfil tallado hechas en China con sus maquinillas de vidrio"; dos "cestos de marfil tallado hechos en la India con sus campanas de vidrio"; y un "cesto de concha de tortuga tallada hecho en la India, adornado con marfil y con su campana de vidrio".

Varios relojes forman también parte del legado de la soberana portuguesa: relojes de caoba; relojes de mesa de palo santo con ornamentos de metal dorado; reloj de sobremesa, en madera de caoba, con figuras de jaspe; reloj de sobremesa, de "madera fingiendo ébano", esfera de plata y decorado con pies y argollas de plata; reloj de sobremesa, cuadrado, de mármol; reloj de caja alta, con caja de caoba (salón comedor); y un "organillo [realejo], con piedra azul por encima, madera de caoba con decoración de metal fino francés, con reloj en el frontal que da las horas con música".

Es muy probable que la colección de la soberana portuguesa contara con otros relojes que tal vez hubiesen resultado dañados durante la invasión francesa, cuando fueron escondidos, como refiere el almojarife João dos Santos: "Hoy, que es 2 de enero, acabo de abrir las cajas [...] que João Diogo había mandado embalar y veo que hay muchas cosas perdidas, principalmente los relojes, que todos están perdidos, no solo de herrumbre, sino muy arruinados por su mala ventilación" 54 .

En los inventarios del Palacio de Ramalhão, entre sus muchas pinturas, muebles, plata y vajillas, merece ser destacado un "Fragmento de Verónica de Jesucristo, de perfil, en relieve sobre fondo de mármol verde antiguo, marco de madera con su plinto con círculos de laureles de metal

\footnotetext{
53 "Documentos de Despesa da Casa Real e Outros". ANTT, CR, caja 4663. Traducido del original portugués.

54 "Carta de João Santos para D. Carlota Joaquina", 3 de enero de 1811. ANTT, Casa das Rainhas, mazo 241, n. ${ }^{\circ}$ 35. Traducido del original portugués.
} 
dorado, con relicario en el centro" y un conjunto de cruces que habían estado en la capilla, más específicamente: una cruz grande con una imagen de madera del Santo Cristo; una cruz "con peana hecha en la India, de tortuga, toda decorada en cobre de Macao, plateada"; una cruz de ébano con peana de palo santo y con imagen de marfil; y una cruz con la imagen del Santo Cristo en marfil, que está en la capilla mayor ${ }^{55}$.

\section{La realización de subastas y la dispersión del legado}

Ante la noticia de la venta del legado de la reina Carlota Joaquina, los miembros de la Real Academia de Bellas Artes de Lisboa no se mostraron indiferentes. En su reunión del 15 de enero de 1844 aprobaron remitir al gobierno una propuesta para la adquisición de algunas obras ${ }^{56}$. En la prensa, por su parte, las voces críticas no se hicieron esperar. Ribeiro de Sá publicó en $O$ Panorama "Um Brado a Favor da Gloria Nacional e das Bellas Artes" [Un grito en favor de la gloria nacional y las Bellas Artes], donde tilda la decisión de vender el legado de Carlota Joaquina como un acto de "moderno vandalismo". El escritor temía que las circunstancias propiciaran la salida de muchas de las obras al extranjero, debido sobre todo a los valores tan reducidos con que habían sido tasadas, a la vez que denunciaba la torpeza del gobierno portugués ante la dispersión de lo que consideraba "primores del arte" y "riquísimos vestigios de una gran riqueza". Ribeiro de Sá pretendía, de esta forma, llamar la atención del gobierno y de las Cortes sobre "una colección preciosa y digna de no ser separada y vendida como despojos a los que no se da valor" 57.

Debido a los retrasos en la partición de la herencia de Carlota Joaquina, solo el 9 de diciembre de 1847, acabada la exigente y meticulosa tarea de embalar y transportar miles de piezas, y una vez conferidos con los inventarios todos los bienes depositados en el Palacio da Bemposta, se inicia la venta de objetos de arte más importante realizada en Portugal hasta ese momento. Inaugurada por el mobiliario, la plata, la porcelana y demás objetos decorativos, el 18 de abril de 1848 se divulgaba en la prensa periódica la exposición y venta de los cuadros, acompañada de información sobre el modo como se llevaría a cabo ${ }^{58}$.

Las licitaciones se prolongaron hasta 1855, cuando fueron "vendidos en subasta, el 4 de noviembre de 1855, el resto de los objetos pertenecientes a la herencia [...] que existían en el Palacio de Ramalhão"59. Un análisis minucioso de la extensa documentación producida — que no cabe en este estudio- permitiría identificar a los muchos compradores y coleccionistas ${ }^{60}$ que fueron adquiriendo cuadros y otras obras de arte procedentes del Palacio de Ramalhão y, de ese modo, seguir el rastro de algunas de esas piezas hasta el día de hoy. Sin embargo, es importante resaltar que el conjunto de bienes adquirido por la Academia de Bellas Artes de Lisboa (c. 1850), aunque no alcanzó todo lo deseado, fue una de las adquisiciones más importantes de dicha institución, tanto por la cantidad y calidad de las obras (27 piezas) como por la inversión pública que supuso ${ }^{61}$. Se trata, efectivamente, de las obras de mayor valor artístico de todo el conjunto, a juzgar por los precios de licitación que le fueron asignados, aunque las atribuciones de autoría resultasen muy dudosas ya en aquel momento, en particular para el ojo crítico del conocido diplomático prusiano Atanazy Raczynski ${ }^{62}$.

De todas formas, hay un aspecto que llama la atención en todo este proceso y que suscita numerosas interrogantes: el número de cuadros licitados. A partir de los inventarios se identifi-

55 "Inventario", 1835, ANTT, CR, caja 4663. Traducido del original portugués.

56 Xavier, 2018: 74. Bastos, 2014: 18.

57 O Panorama, 109, 27-I-1844, pp. 27-28.

58 Diário do Governo, 93, 18-IV-1848, p. 478.

59 ANTT, CR, caja 7100, legajo XX/Z/81(20).

${ }^{60}$ Bastos, 2014: 24.

${ }^{61}$ Bastos, 2014: 18-26. Soares, 2017: 26-27. Xavier, 2018: 64. En estos estudios se identifican las obras compradas por la Academia de Bellas Artes de Lisboa, que en la actualidad forman parte de las colecciones del Museo Nacional de Arte Antigua

${ }^{62}$ Raczynski, 1846: 283. En los cuadros adquiridos para la Academia de Bellas Artes de Lisboa en 1868 ya se hacían notar algunas revisiones de autoría y ciertas alteraciones en los títulos. Holstein, 1868. 
caron cerca de 190, lo que nos sitúa ante un número muy cercano al contabilizado en 1807 en la 'Casa de la Pintura' del Palacio de Ramalhão, donde, como ya hemos referido anteriormente, constaban 180 pinturas $^{63}$. Considerando que los bienes de la herencia de Carlos IV apenas se incorporan tras 1826, cuando se inician las particiones, es fundamental dilucidar la dinámica de la colección de pintura de Carlota Joaquina antes y después de su muerte. Solo conseguiremos comprender cabalmente estos números si atendemos a las circunstancias políticas de la época, a las opciones estéticas, a la larga ausencia de 14 años en que la soberana vivió en Brasil y, claro está, a las vicisitudes que rodearon las particiones de su herencia.

\section{Consideraciones finales}

El interés suscitado por la colección de pintura de la reina Carlota Joaquina de Borbón ha dado lugar a varios estudios que nos permiten conocer detalles importantes de las obras que formaban parte de ella, así como de los mecanismos que condujeron a su dispersión entre los herederos, del mercado del arte y de la Real Academia de Bellas Artes de Lisboa. La adquisición por el Estado portugués de 27 obras pertenecientes a la colección (25 pinturas y dos esculturas), durante la subasta que se inicia en el Palacio da Bemposta en 1847, también se encuentra ya clarificada. Ahora contamos con un conocimiento histórico, artístico y material más profundo de algunas de esas obras. En este contexto, los estudios que en 2014 se centraron en el análisis del Éxtasis de San Francisco - atribuido desde hace unas décadas a Luca Giordano- han permitido poner de manifiesto nuevas e importantes cuestiones relacionadas con la procedencia de esta obra y de otras que también pertenecieron a las colecciones de doña Carlota Joaquina, así como de los intrincados meandros de las particiones del legado dejado en herencia por la soberana.

Con todo, aún nos faltan respuestas a preguntas tan elementales como cuándo, dónde, a quién o en qué circunstancias se adquirieron las muchas obras que integraron dichas colecciones. Determinar los agentes y canales de circulación de los objetos pertenecientes al legado de la soberana portuguesa ayudará, en el futuro, a definir con mayor precisión el gusto y la sensibilidad artística de doña Carlota Joaquina y su perfil de coleccionista.

El propio inventario que aquí hemos presentado, a semejanza de otros de la época, nacionales o extranjeros, presenta fragilidades y ambigüedades fácilmente detectables, en particular en lo relativo a la precipitación de las atribuciones y a las imprecisiones iconográficas, hechos que condicionan la correspondencia con inventarios más recientes, donde las imágenes fotográficas son determinantes.

Así y todo, con la divulgación de las pinturas inventariadas en el Palacio de Ramalhão en 1835 (Tabla I) — que incluyen notas sobre el tema representado, la autoría o atribución de autoría y sus dimensiones-, esperamos haber proporcionado datos que permitan que otros investigadores prosigan con la identificación del origen de las piezas — en particular las heredadas de Carlos IV, sobre todo cotejando los inventarios de la testamentaría romana de Carlos IV conservada en los archivos de Madrid - y en el rastreo del recorrido que han seguido desde que fueron subastadas en el Palacio da Bemposta y entraron en el circuito del mercado del arte hasta que acabaron por integrarse en diversas colecciones públicas y privadas.

\section{BIBLIOGRAFÍA}

Alves, Alice (2015): “O Restauro de Pintura na Academia de Belas-Artes de Lisboa - A contribuição de António Manuel da Fonsec [sic]". En: Arte Teoria, 16-17, Faculdade de Belas Artes da Universidade de Lisboa, pp. 97-105.

Araújo, Agostinho (2009): "O restauro de painéis e a actividade de alguns pintores italianos em Portugal (ca. 17101860)". En: Topa, Francisco/Marnoto, Rita (eds.): Nel mezzo del cammin: Actas da jornada de estudos italianos em honra de Giuseppe Mea. Oporto: Universidade do Porto, pp. 11-63.

${ }^{63}$ Inventário de toda a mobilia que Existe no Real Paço do Ramalhão (...). ANTT, Casa das Rainhas, Libro 234. 
Bastos, Celina (2014): "Percurso de uma obra”. Luca Giordano Êxtase de São Francisco. Lisboa: MNAA, pp. 6-32.

Blanco, Francisco Cordeiro (1938): "Uma carta inédita de Vieira Portuense". En Boletim do Museu Nacional de Arte Antiga, I, 3. Lisboa: s/e, pp. 147-151.

Carvalho, Ayres de (1982): A galeria de pintura da Ajuda e as galerias do século XIX. Lisboa: [s. i.].

García-Frías, Carmen (2011): "Nuevas aportaciones al estudio de la colección pictórica de Carlos IV en el exilio". En: Rodríguez G. de Ceballos, Alfonso/Rodríguez Rebollo, Ángel (eds.): Actas de las Jornadas de Arte e Iconografia sobre Calos IV y el arte de su reinado. Madrid: Fundación Universitaria Española, pp. 211-261.

Hermoso Cuesta, Miguel (2005): "Un cuadro del Museu Nacional de Arte Antiga en Lisboa procedente de la colección de Carlos IV”. En: Reales Sitios, 165, tomo XLII. Madrid: Patrimonio Nacional, pp. 74-77.

Hermoso Cuesta, Miguel (2010): “A propósito de un lienzo de Lucas Jordán en el Museu Nacional de Arte Antiga de Lisboa". En: Anales de Historia del Arte, 20. Madrid: Universidad Complutense, pp. 183-207.

Jordán de Urríes, Javier (2009): "El gusto de Carlos IV en sus casas de campo". En: Jordán de Urríes, Javier y Sancho, José Luis (eds.): Carlos IV. Mecenas y Coleccionista - Cat. Exposición. Madrid: Patrimonio Nacional/Sociedad Estatal de Conmemoraciones Culturales.

Luna, Juan J. (1992): Carlos IV, mecenas de pintores y coleccionista de pinturas [Discurso de ingreso en la Real Academia de Doctores]. Madrid: Real Academia de Doctores de Madrid.

Machado, Cyrillo Volkmar (1823): Collecção de Memorias, relativas às vidas dos pintores, e escultores, architetos, $e$ gravadores portuguezes, E dos Estrangeiros, que estiverão em Portugal. Lisboa: Imp. de Victorino Rodrigues da Silva.

Presas, José (1830): Memorias secretas de la princesa del Brasil, actual reina viuda de Portugal, la señora doña Carlota Joaquina de Borbón. Burdeos: Casa de Carlos Lawalle Sobrino.

Raczynski, A. (1846): Les Arts en Portugal. Paris: Jules Renouard et Cie., Libraires-Éditeurs.

Reyero, Carlos (2014): "Taxació i compravenda de pintures a mitjan segle XIX". En Bassegoda, Bonaventura/Domènech, Ignasi (eds.): Mercat de l'art, colleccionisme $i$ museus. Estudis sobre el patrimoni artístic a Catalunya als segles XIX $i$ XX. Barcelona: Universitat Autònoma de Barcelona, pp. 153-205.

Sá, Sebastião José Ribeiro de (1844): "Um Brado a Favor da Gloria Nacional e das Bellas Artes”. En: O Panorama, 109. Lisboa: Typographia da Sociedade, pp. 27-28.

Sá, Sebastião José Ribeiro de (1848): "Os quadros da Bemposta e a possibilidade de organizar em Lisboa um Muzeu Nacional”. En: Revista Universal Lisbonense, vol. VII. Lisboa: Imprensa Nacional, pp. 241-246 y 254-258.

Sancho, José Luis (2008): "Coleccionista hasta la muerte. Casas y obras artísticas de Carlos IV en Francia y en Roma, 1808-1819”. En: Reales Sitios, 175, tomo XLV, pp. 4-25.

Santos, Paula Mesquita (1995): “A Coleção de pintura de D. Carlota Joaquina de Bourbon, oriunda do Ramalhão, em Sintra”. En: Varia Escrita: Cadernos de estudos arquivísticos, históricos e documentais, 2. Sintra: Câmara Municipal de Sintra, pp. 261-299.

Saraiva, José da Cunha (1935): "Os quadros do Ramalhão que foram para a Academia de Belas Artes". En: Feira da Ladra - revista mensal ilustrada, VII. Lisboa, pp. 165-177.

Soares, Clara Moura (2014a): "Na origem da Galeria Nacional de Pintura da Academia de Belas-Artes de Lisboa: 540 quadros selecionados do Depósito das Livrarias dos Extintos Conventos". En: Artis - Revista de História da Arte e Ciências do Património, 2. Lisboa: Caleidoscópio, pp. 200-201.

Soares, Clara Moura (2014b): "D. Pedro, I do Brasil, IV de Portugal - O 'Gosto do Bello' e o incremento das Belas-Artes: traços de um perfil quase desconhecido do Rei-Soldado". En: Neto, Maria João/Malta, Marize (eds.): Coleções de Arte em Portugal e Brasil nos séculos XIX e XX. Perfis e trânsitos. Casal de Cambra: Caleidoscópio, pp. 381-398.

Soares, Clara Moura (2017): "Os Recheios do Paço do Ramalhão (Sintra, Portugal): a herança e o gosto artístico da rainha D. Carlota Joaquina de Bourbon”. En: Cavalcanti, Ana/Valle, Arthur/Neto, Maria João/Malta, Marize/ Pereira, Sonia Gomes (coords.): Arte e seus lugares: coleções em espaços reais: Anais do VIII Seminário do Museu D. João VI / IV Colóquio Internacional Coleções de Arte em Portugal e Brasil nos séculos XIX e XX. Río de Janeiro: UFRJ, EBA/PPGAV; UFRJ, Museu D. João VI, pp. 11-32.

Sousa Holstein, Marquês de (1868): Catalogo provisorio da Galeria Nacional de Pintura existente na Academia Real das Bellas Artes de Lisboa. Lisboa: Academia Real das Bellas Artes.

Urriagli Serrano, Diana (2011): “Cuadros reunidos por Carlos IV en sus casas de campo". En: Rodríguez G. de Ceballos, Alfonso/Rodríguez Rebollo, Ángel (eds.): Actas de las Jornadas de Arte e Iconografía sobre Calos IV y el arte de su reinado. Seminario de Arte e Iconografia 'Marqués de Lozoya'. Madrid: Fundación Universitaria Española, pp. 141-210.

Urriagli Serrano, Diana (2012): Las Colecciones de Pinturas de Carlos IV en España. Madrid: Fundación Universitaria Española.

Villa-Urrutia, Marqués de (1919): El Palacio Barberini. Recuerdos de España en Roma. Madrid: Francisco Beltrán, Librería Española y Extranjera.

Xavier, Hugo (2018): O Marquês de Sousa Holstein e a Formação da Galeria Nacional de Pintura da Academia de Belas Artes de Lisboa. Casal de Cambra: Caleidoscópio/Património Cultural, Direção-Geral do Património Cultural.

Fecha de recepción: 12-VI-2019

Fecha de aceptación: 04-XI-2019 